\title{
Atributos físico-espaciais e configuracionais de segmentos de ruas e ocorrências de roubos a pedestres
}

\author{
Physical-spatial and configurational attributes of street \\ segments and occurrences of pedestrian mugging
}

\section{Antônio Tarcísio da Luz Reis Clarel Fernando Ely J unior Camila da Silva Eisenhut}

\section{Resumo}

${ }^{1}$ Antônio Tarcísio da Luz Reis ${ }^{1}$ Universidade Federal do Rio Grande Porto Alegre - RS https:// orcid. org/ 0000-0002-2010-0688

${ }^{2}$ Clarel Fernando Ely J unior ${ }^{2}$ Universidade Federal do Rio Grande do Sul Porto Alegre - RS - Brasil

${ }^{3}$ Camila da Silva Eisenhut ${ }^{3}$ Universidade Federal do Rio Grande do Sul Porto Alegre - RS - Brasil

Recebido em 18/09/18 Aceito em 07/01/19

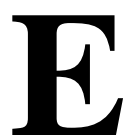

ste artigo trata das relações entre as ocorrências de roubos a pedestres em diferentes turnos e atributos físico-espaciais e configuracionais de segmentos de ruas nos 22 bairros na região central de Porto Alegre, incluindo comprimento do segmento, conectividade, integração e escolha, conexões físicas e visuais, barreiras físicas e visuais, postes de luz, número de portas de garagem, tipos de uso das edificações e os usos no pavimento térreo durante cada um dos quatro turnos. Ainda, são considerados o dia da semana, mês e ano no qual o roubo a pedestre ocorreu. As ocorrências de roubos a pedestres foram coletadas na plataforma digital "Onde fui roubado" no período de $1^{\circ}$ de janeiro de 2012 a 31 de março de 2016. Os dados obtidos foram registrados no programa QGIS sobre uma imagem de satélite da região associada a um mapa de segmentos gerado pelo programa Depthmap. Adicionalmente, foram realizadas análises estatísticas com o programa SPSS/PC. Os resultados mostram a tendência de o roubo a pedestre ocorrer nos turnos da noite e da tarde e em segmentos de ruas pouco iluminados, com baixos níveis de conexão física e visual entre as edificações e os espaços abertos públicos, com pouca quantidade de edificações de uso misto, residencial e comercial/serviços, e com pequena quantidade de usos residenciais e de atividades de serviços e comerciais nos pavimentos térreos.

Palavras-chave: Roubo a pedestre. Segmento de rua. Crime na rua.

\section{Abstract}

This paper deals with the relationship between occurrences of pedestrian mugging in different periods of the day and the physical-spatial and configurational attributes of street segments in the 22 neighbourhoods in the central region of Porto Alegre, including: segment length, connectivity, integration and choice, physical and visual connections, physical and visual barriers, lampposts, number of garage doors, types of building use, and uses at ground floor during each of the four periods of the day. In addition, the day of the week, month and year in which the pedestrian mugging occurred is considered. The occurrences of pedestrian mugging were collected through the digital platform "Where I was mugged" and cover the period from 01/01/12 to 31/03/16. The data obtained were recorded in the QGIS program, based on a satellite image of the region and associated to a segment map generated by the Depthmap program. In addition, statistical analyses were performed using the SPSS/PC program. The results show a tendency of pedestrian muggings to occur during the night and afternoon periods and in poorly lit street segments with low levels of physical and visual connections between buildings and open public spaces, with few buildings for residential, commercial/services and mixed uses, and with a small amount of residential uses and services and commercial activities on the ground floors.

Keywords: Pedestrian mugging. Street segments attributes. Street crime.

REIS, A. T. da L.; ELY J UNIOR, C. F.; EISENHUT, C. da S. Atributos físico-espaciais e configuracionais de segmentos de 55 ruas e ocorrências de roubos a pedestres. Ambiente Construído, Porto Alegre, v. 19, n. 4, p. 55-77, out./dez. 2019. ISSN 1678-8621 Associação Nacional de Tecnologia do Ambiente Construído. http:// dx. doi. org/ 10.1590/ s1678-86212019000400343 


\section{Introdução}

A insegurança urbana quanto à ocorrência de crimes, embora não seja exclusiva de cidades brasileiras, tem afetado severamente a qualidade de vida em diversas cidades do país (LIRA, 2014; MONTEIRO; CAVALCANTI, 2017; REIS; DITTMAR, 2012; ZALUAR, 2002). Particularmente, as ocorrências de roubos a pedestres em cidades como Porto Alegre têm sido, durante o período de 2010 a 2017, muito mais numerosas (37.397) do que outros tipos de crimes nas ruas, tais como furto em veículo (17.660), roubo de veículo (15.528) e furto de veículo (8.168), conforme informações da Diplanco, do Serviço de Estatística da Polícia Civil do Estado do Rio Grande do Sul.

Aspectos tais como os sociais, econômicos e políticos podem potencializar ou minimizar ações criminosas em áreas urbanas, e alguns estudos têm focado nos efeitos da insegurança no espaço urbano (CALDEIRA, 2000; ZALUAR, 2002). Por sua vez, outros estudos realizados em distintas cidades de diferentes países têm tido como objetivo a verificação dos efeitos da forma e da configuração urbana nas ocorrências de crimes, e têm mostrado que diversas variáveis físico-espaciais e configuracionais estão relacionadas à prevenção ou redução das possibilidades de crime, incluindo roubo a pedestre (HILLIER; SAHBAZ, 2012; NEWMAN, 1972, 1976; POYNER; WEBB, 1991; SHU, 2009; VAN NES; LÓPEZ, 2010; VOORDT; WEGEN, 1993). Enquanto as variáveis físicoespaciais tratam das características físico-espaciais de uma quadra (p. ex., quantidade de postes de luz), as variáveis configuracionais dizem respeito a características da quadra em relação às outras quadras da região considerada (p. ex., níveis de acessibilidade representados pela variável integração) (HILLIER; HANSON, 1984). O roubo a pedestre pode ser entendido como o assalto ao pedestre ou como o crime em que o delinquente exerce alguma ameaça ou agressão com uma arma branca ou de fogo para apoderar-se de pertences da vítima (MONTEIRO; CAVALCANTI, 2017). Sahbaz e Hillier (2007) ressaltam que o roubo a pedestre constitui um medo diário na vida urbana e que a redução dos tipos de ambientes mais prováveis de tal crime ocorrer deveria ser um objetivo a ser alcançado, visando espaços urbanos que possam ser usados efetivamente de dia e de noite.

Contudo, o roubo a pedestre tem sido pouco considerado nas pesquisas sobre as relações entre ocorrências de crimes e características físicas e configuracionais das áreas urbanas (CHIARADIA; HILLIER; SCHWANDER, 2009; SAHBAZ;
HILLIER, 2007). Sahbaz e Hillier (2007) já haviam destacado que:

A pesquisa sobre crime com base no ambiente construído, até agora, raramente focou no roubo a pedestre. A razão para isso pode ser a dificuldade em saber exatamente onde um assalto aconteceu, ou as precauções contra o roubo a pedestre pareceram menos aplicáveis do que a outros crimes como roubos em residências, $e$, portanto, este tipo de pesquisa sendo percebida como mais valiosa. (SAHBAZ; HILLIER, 2007, p. 1).

Assim, Ceccato e Oberwittler (2008) citam que poucos estudos sobre crimes em cidades na Europa Oriental, na fase pós-socialista, relatam a natureza dos crimes e muito pouco é encontrado sobre roubos a pedestres. Adicionalmente, devido à dificuldade de obtenção de dados detalhados sobre ocorrências criminais, muitos estudos não têm considerado as variações espaciais e temporais de tais ocorrências nos espaços urbanos (CECCATO; OBERWITTLER, 2008). Além disso, diferentes abordagens em relação a tipos de crimes e turnos do dia em que o crime ocorre têm sido consideradas em distintos estudos, com poucos fazendo a distinção entre períodos de ocorrência criminal e tipos de variáveis envolvidas (MONTEIRO; IANNICELLI, 2009).

Ainda, não existem evidências conclusivas acerca das relações entre variáveis físico-espaciais e configuracionais e as ocorrências de roubos a pedestres em diferentes horários; por exemplo, não existem definições acerca dos níveis aceitáveis de conexões físicas e visuais entre as edificações e as ruas para que estas sejam mais seguras em distintos períodos do dia. As conexões físicas, também chamadas de "constituição" em estudos que envolvem análise sintática (MONTEIRO; CAVALCANTI, 2017), permitem o movimento de pessoas entre o interior de uma edificação e o espaço aberto público adjacente, enquanto as conexões visuais permitem que as pessoas no interior de uma edificação possam visualizar os espaços abertos públicos adjacentes, também denominadas de "visibilidade" por alguns autores quando consideradas em conjunto com as conexões físicas (VIVAN; SABOYA, 2017). Também é necessário entender melhor as razões para as ocorrências de crimes ao nível das características das quadras das ruas, de forma a realizar uma análise detalhada dos padrões criminais no sistema de ruas de uma cidade, onde muitas variáveis estão envolvidas (HILLIER; SAHBAZ, 2005). Nesse sentido, é importante realizar uma análise das 
ocorrências criminais no nível do segmento de rua, que tende a corresponder a uma quadra urbana. $\mathrm{O}$ segmento é gerado pelo cruzamento e a consequente segmentação de linhas axiais (HILLIER; IIDA, 2005), sendo essas as linhas retas mais longas que representam as extensões máximas de ruas e caminhos em um mapa axial (HILLIER; HANSON, 1984). Assim, existe a necessidade de aprofundar o conhecimento a respeito das relações entre roubos a pedestres em diferentes turnos do dia e atributos físico-espaciais e configuracionais de distintos segmentos de ruas. Portanto, o objetivo deste artigo é investigar a ocorrência de roubo a pedestre em diferentes turnos do dia (manhã, tarde, noite e madrugada) e sua relação com atributos físicoespaciais e configuracionais dos segmentos nos 22 bairros mais centrais de Porto Alegre, incluindo comprimento do segmento, conectividade, integração e escolha, conexões físicas e conexões visuais, barreiras físicas e visuais (p. ex., muros), postes de luz, número de portas de garagem, tipos de usos dos edifícios e os usos no pavimento térreo durante cada um dos quatro turnos. Adicionalmente, outros atributos temporais são considerados, tais como dia da semana, mês e ano nos quais o roubo a pedestre ocorreu.

\section{Método}

Os 22 bairros na área mais central de Porto Alegre (Figura 1) foram selecionados devido à alta concentração de crimes nas ruas e ao fato de que eles compõem as áreas urbanas mais densas e consolidadas, permitindo a identificação dos atributos físico-espaciais dos segmentos.

\section{Figura 1 - Bairros selecionados na região central de Porto Alegre}

Nota: Legenda:

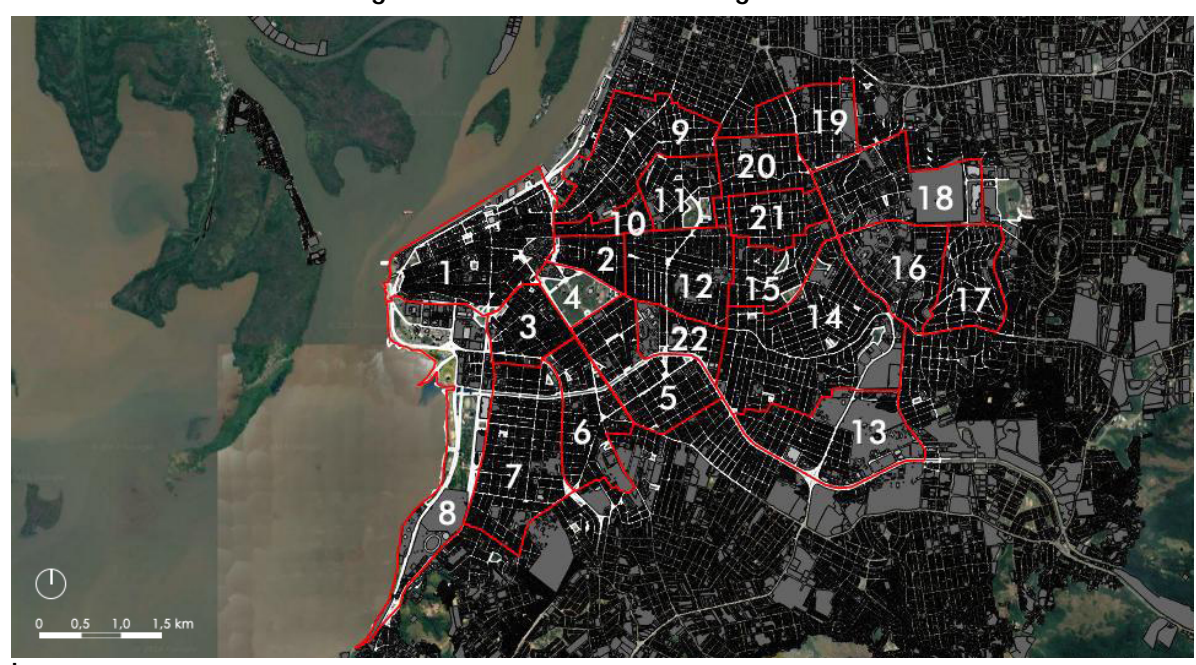

1 = Centro Histórico;

2 = Bom Fim;

3 = Cidade Baixa;

4 = Farroupilha;

5 = Santana;

6 = Azenha;

7 = Menino Deus;

8 = Praia de Belas;

9 = Floresta;

$10=$ Independência

11 = Moinhos de Vento;

$12=$ Rio Branco;

$13=$ J ardim Botânico;

14 = Petrópolis;

15 = Bela Vista;

$16=$ Três Figueiras;

$17=$ Chácara das Pedras;

18 = Boa Vista;

19 = Higienópolis;

20 = Auxiliadora;

21 = Mont' Serrat; e

22 = Santa Cecília. 
Dados relacionados às ocorrências de roubo a pedestre foram coletados de $1^{\circ}$ de janeiro de 2012 a 31 de março de 2016, totalizando 4 anos e 3 meses, na plataforma digital "Onde fui roubado" (http://www.ondefuiroubado.com.br/), que também é um aplicativo que permite à vítima marcar em um mapa da cidade o local/endereço (nome da rua e número mais próximo) onde o roubo ocorreu e preencher informações como horário, data, itens roubados e uma pequena descrição do roubo. $\mathrm{O}$ fato de ser necessário estar ciente da existência da plataforma e ter acesso à internet para poder registrar o crime pode ter tido algum efeito no tipo de vítima que informou as ocorrências. Assim, tais registros podem ter sido feitos predominantemente por estudantes, funcionários e professores da Universidade Federal do Rio Grande do Sul (UFRGS), que se localiza próximo a vários segmentos com as maiores ocorrências de roubo a pedestre. Portanto, para evitar distorção (p. ex., na consideração de segmentos em regiões não utilizadas pelos estudantes, funcionários e professores), a seleção dos segmentos sem roubo a pedestre foi realizada considerando o máximo de três passos de profundidade de um segmento com roubo a pedestre, isto é, considerando a distância máxima de três quadras a partir da quadra com roubo a pedestre. Dessa forma, os segmentos com as maiores ocorrências de roubo a pedestre e aqueles sem tais ocorrências, considerados na análise, estão próximos uns dos outros.

As informações obtidas acerca dos roubos a pedestres foram registradas no programa QuantumGIS, sobre uma imagem de satélite associada a um mapa de segmentos de Porto Alegre gerado pelo Depthmap a partir do mapa axial. Atributos dos segmentos, como comprimento do segmento, conectividade, valores de integração global (Figura 2) e integração local dos segmentos, e valores de escolha de rota global e local dos segmentos foram obtidos mediante a análise do mapa de segmentos no Depthmap para toda a região compreendida pelos 22 bairros. Conforme salientado por Hillier e Iida (2005), a análise de segmentos tem a vantagem sobre a análise de linhas axiais por ser mais detalhada e por melhor potencializar a geração de correlação com a análise de movimento.

A conectividade mede o número de espaços conectados diretamente com um espaço de origem, indicando o número de conexões de um segmento com outros segmentos, e varia de 1 (p. ex., para o último segmento em um cul-de-sac) a 6 (para um segmento em um sistema do tipo grelha, onde o segmento se conecta com outros três em cada uma das extremidades) (HILLIER; HANSON, 1984; HILLIER; SAHBAZ, 2005). A integração mede o potencial que um espaço ou segmento tem como destino para o movimento em relação a todos os demais segmentos do sistema em questão (integração global) ou em relação apenas aos segmentos que se enquadram na distância considerada a partir do segmento em questão (integração local) (HILLIER; HANSON, 1984; HILLIER; IIDA, 2005). Por sua vez, os níveis de escolha de rota indicam o potencial de movimento através de cada espaço ou segmento como parte de um percurso (HILLIER; IIDA, 2005). Integração e escolha foram medidos considerando os níveis global (todos os segmentos na região considerada com os 22 bairros) e local (R750 metric considerados apenas os segmentos dentro de um raio de $750 \mathrm{~m}$ ). Esse raio foi utilizado por estar dentro do limite de $800 \mathrm{~m}$, considerado como adequado por muitos pesquisadores que utilizam análise sintática para melhor explicitar o movimento local (HILLIER, 2007).

Figura 2 - Mapa de segmentos da região central de Porto Alegre - Integração global Rn

Nota: Legenda:

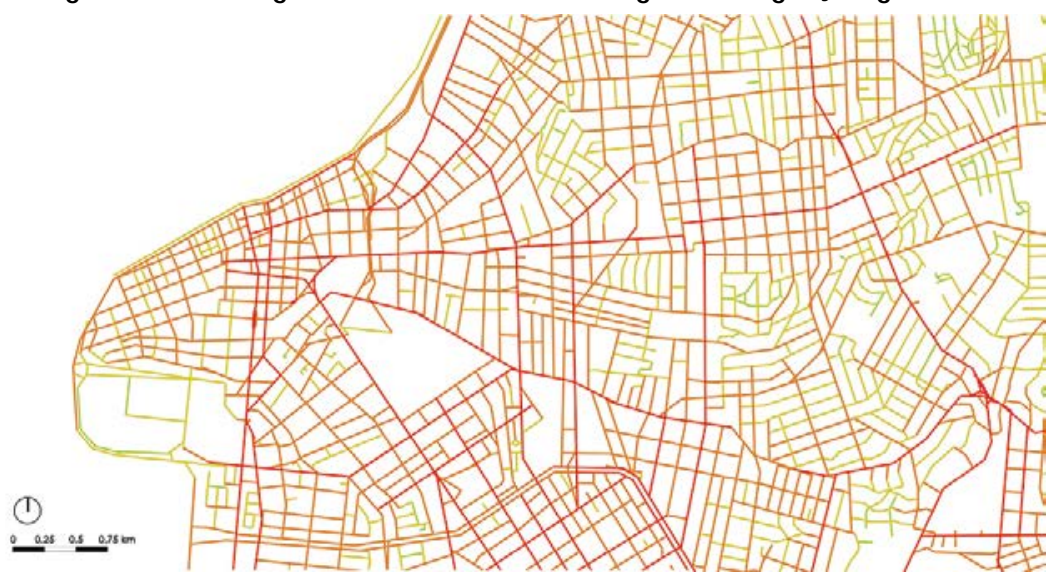

segmentos mais avermelhados = valores mais altos de integração global; e segmentos mais esverdeados = valores mais baixos de integração global. 
Os seguintes atributos foram identificados e quantificados através do Google Street View para 30 segmentos sem nenhum roubo a pedestre em qualquer um dos quatro turnos do dia (Figura 3) e para os 10 segmentos com mais roubos a pedestres (variando de 2 a 10 roubos em um segmento) em cada turno (Figuras 4, 5, 6 e 7; 28 segmentos diferentes, visto que 12 segmentos foram selecionados para mais de um turno) em um total de
58 segmentos: conexões físicas, conexões visuais, barreiras físicas e visuais, postes de luz e portas de garagem. Tipos de usos das edificações (residencial, comercial/serviços e uso misto) e os usos durante cada um dos quatro turnos do dia nos térreos (existência ou não de atividade residencial, de serviço ou comercial) foram identificados através de um mapa de usos elaborado pela prefeitura e conferidos com o Google Street View.

Figura 3 - Trinta segmentos sem roubo a pedestre em nenhum turno do dia

Nota: Legenda:
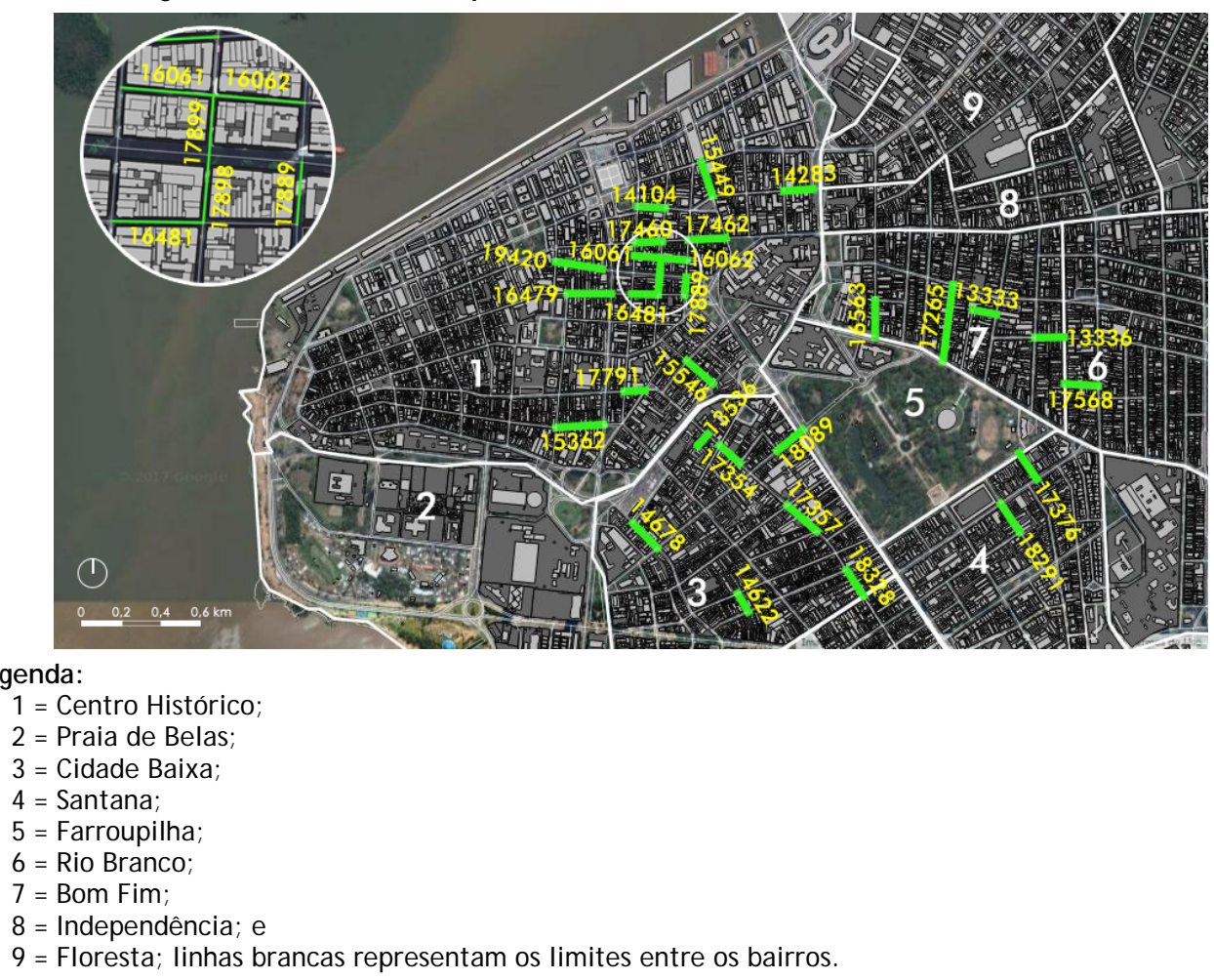

Figura 4 - Dez segmentos com mais roubos a pedestres no turno da manhã

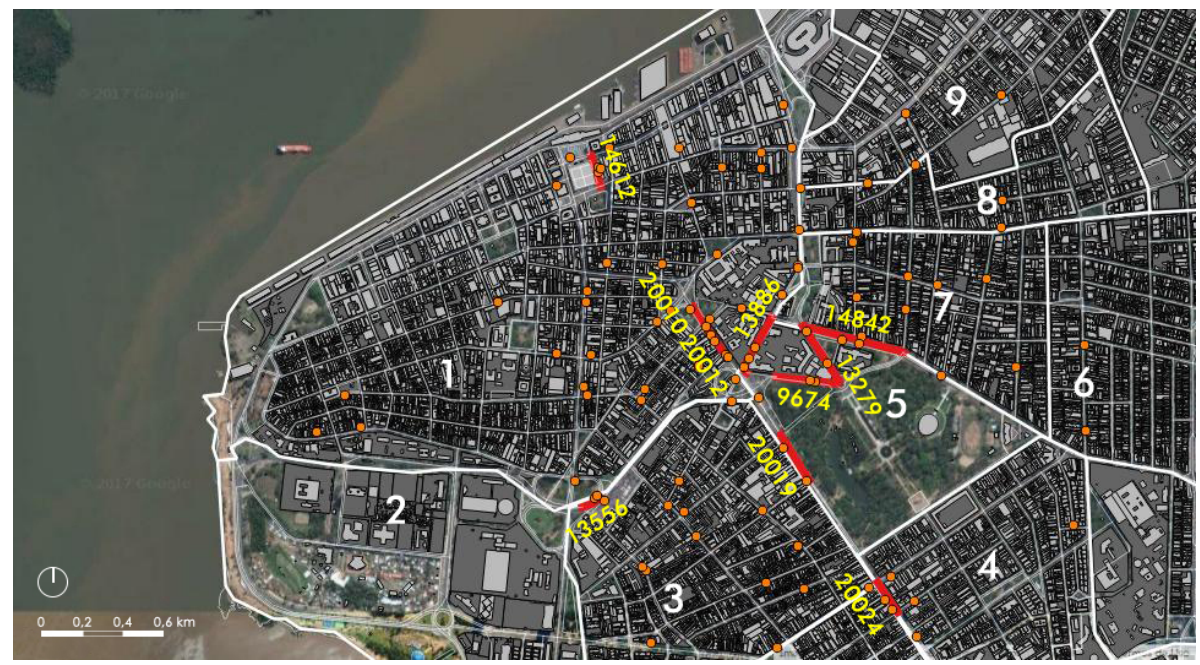

Nota: pontos laranjas = roubo a pedestre no turno da manhã. 
Figura 5 - Dez segmentos com mais roubos a pedestres no turno da tarde

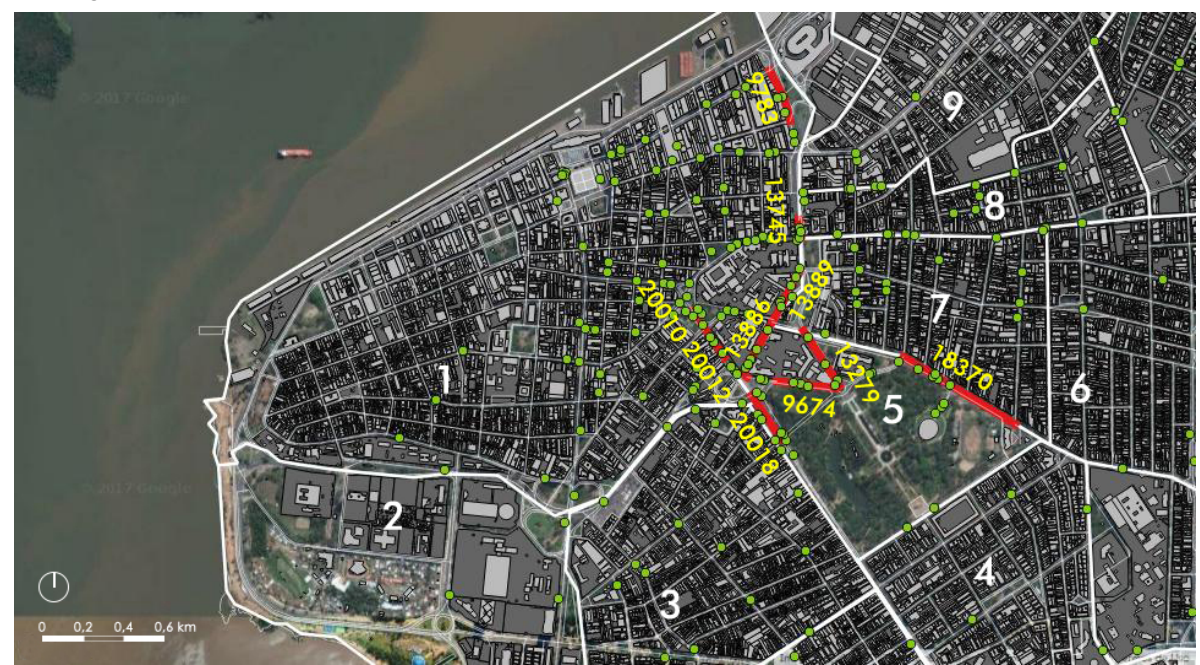

Nota: pontos verdes = roubo a pedestre no turno da tarde.

Figura 6 - Dez segmentos com mais roubos a pedestres no turno da noite

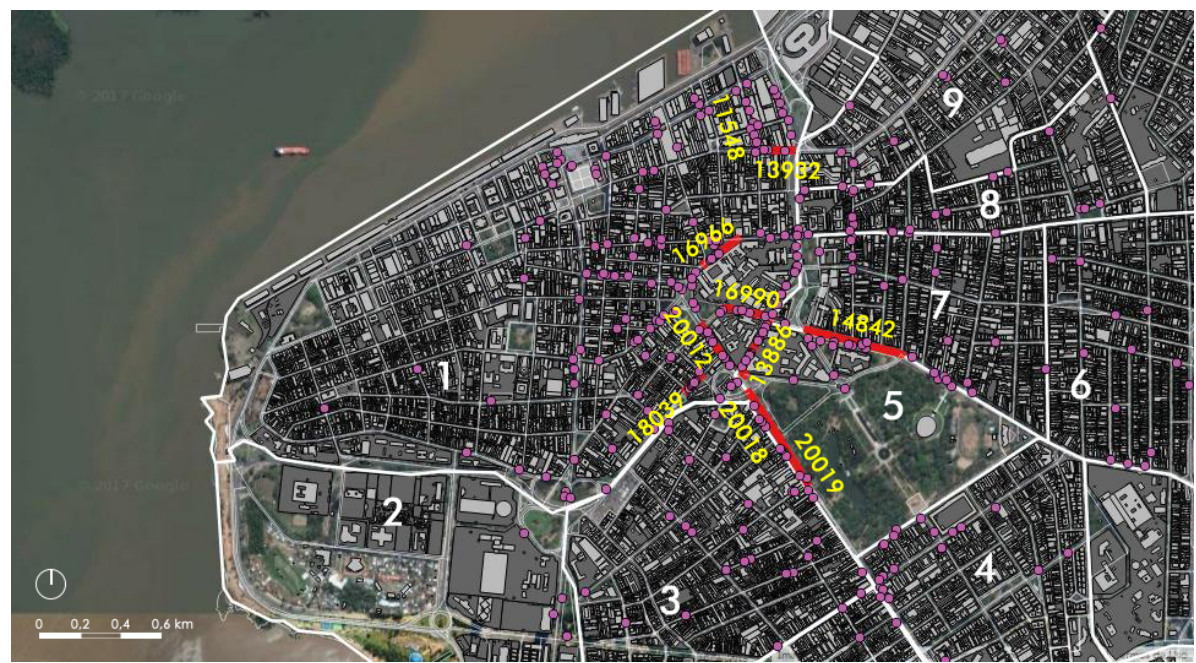

Nota: pontos rosas $=$ roubo a pedestre no turno da noite.

Figura 7 - Dez segmentos com mais roubos a pedestres no turno da madrugada

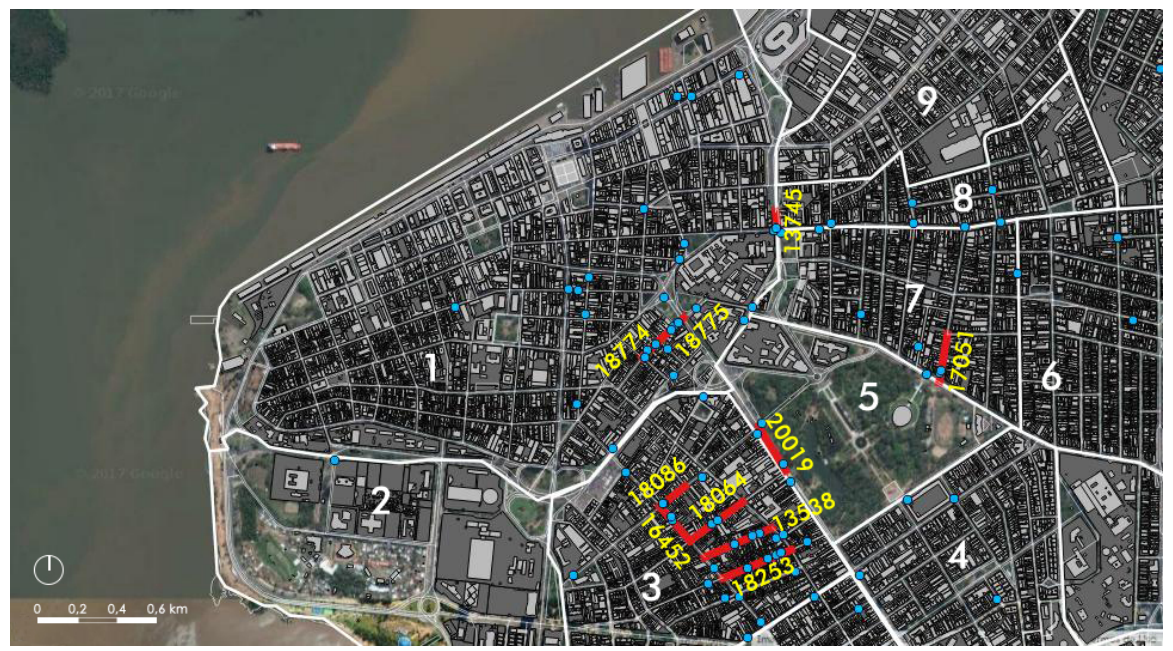

Nota: pontos azuis = roubos a pedestres no turno da madrugada. 
Para permitir comparação entre os diferentes segmentos, para cada atributo foi calculada uma taxa. Assim, as taxas de conexão física foram obtidas pela divisão do número total de conexões físicas (portas térreas que permitem às pessoas acessar as edificações através das calçadas) em ambos os lados do segmento (p. ex., 58 acessos) pelo dobro do comprimento (p. ex., 274,11 $\mathrm{m} \mathrm{x} 2$ = $548,22 \mathrm{~m}$ ), que, nesse exemplo, resulta em uma taxa de conexão física de 0,106 (58 acessos/548,22 m). Isso significa que existe um acesso à edificação a cada 9,45 m (548,22 m/58 acessos), considerando o comprimento resultante da soma dos dois lados desse segmento (548,22 m). As taxas de conexão visual foram calculadas dividindo-se o comprimento total (em metros) de conexões visuais (janelas e portas de vidro que permitem a visualização da rua por parte de quem está no interior da edificação) em ambos os lados da rua (p. ex., $71 \mathrm{~m}$ ) pelo dobro do comprimento (p. ex., 274,11 m x 2 = 548,22 m), que, nesse exemplo, resulta em uma taxa de conexão visual de 0,130 (71 $\mathrm{m} / 548,22 \mathrm{~m})$. Isso significa que somente $13 \%$ do total dos 548,22 m de interfaces térreas (incluídas as fachadas das edificações, muros e outros tipos de interfaces) ao longo dos dois lados da rua são visualmente conectados aos espaços abertos públicos da rua. As taxas de barreiras físicas e visuais (p. ex., muros) foram geradas pela divisão da extensão (em metros) dessas barreiras em ambos os lados do segmento pelo dobro de seu comprimento. As taxas de poste de luz foram obtidas pela divisão do número de postes de luz ao longo do segmento por seu comprimento. As portas de garagem foram calculadas dividindo-se a extensão das portas (em metros) em ambos os lados do segmento pelo dobro de seu comprimento.

As taxas de uso residencial, comercial/serviços e uso misto foram geradas pela divisão do número de edificações com cada tipo de uso em ambos os lados do segmento pelo dobro do comprimento. As taxas de atividade residencial, de serviço e comercial nos térreos das edificações voltados para a rua, nos diferentes turnos, foram obtidas pela divisão da quantidade de cada um desses tipos de atividade em ambos os lados do segmento pelo dobro de seu comprimento. Assim, com exceção da taxa de postes de luz, que é um atributo do segmento, e não de cada um de seus lados ou interfaces, as taxas das variáveis são divididas pelo dobro do comprimento do segmento, pois dizem respeito a cada um dos dois lados do segmento. Adicionalmente, análises estatísticas foram realizadas no programa SPSS/PC correlacionando (testes de correlação de Spearman) os roubos a pedestres em cada um dos quatro turnos do dia com os atributos dos segmentos.

\section{Resultados}

A maior quantidade de roubos a pedestres nos 28 segmentos selecionados, de 2012 a 2016, tende a ocorrer no turno da noite $(37,4 \%$ - 55 de 147 roubos a pedestres), seguido pelo turno da tarde (29\% - 43 de 147), turno da madrugada (17\% - 25 de 147) e turno da manhã (16,3\% - 24 de 147), este o turno mais seguro para caminhar nas ruas (Figura 8 e Tabela 1).

\section{Figura 8 - Roubo a pedestre em cada um dos quatro turnos do dia}

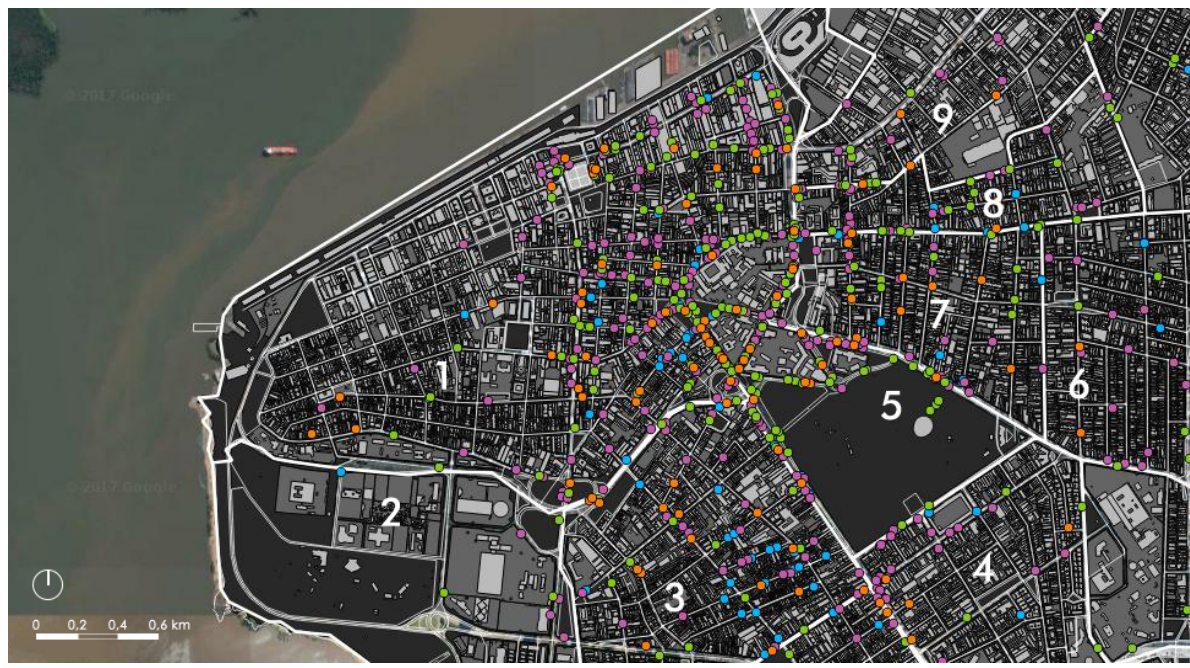

Nota: Legenda: pontos coloridos representam roubo a pedestre nos quatro turnos do dia, como segue:

$$
\text { laranj } \mathrm{a}=\text { = manhã; }
$$

verde $=$ tarde;

rosa $=$ noite; $\mathrm{e}$

azul = roubo a pedestre no turno da madrugada. 
Tabela 1 - Segmentos com mais roubos a pedestres durante o período de janeiro de 2012 a março de 2016

\begin{tabular}{l|c|c|c|c|c|c}
\hline & $\mathbf{2 0 1 2}$ & $\mathbf{2 0 1 3}$ & $\mathbf{2 0 1 4}$ & $\mathbf{2 0 1 5}$ & $\begin{array}{c}\text { Janeiro a } \\
\text { março de } \\
\mathbf{2 0 1 6}\end{array}$ & $\begin{array}{c}\text { Total de } \\
\text { roubos a } \\
\text { pedestres }\end{array}$ \\
\hline $\begin{array}{l}\text { Segmentos com mais } \\
\text { roubos a pedestres no } \\
\text { turno da manhã (10) }\end{array}$ & $1(12,5 \%)$ & $6(12,5 \%)$ & $12(23,1 \%)$ & $2(6,4 \%)$ & $3(37,5 \%)$ & $24(16,3 \%)$ \\
\hline $\begin{array}{l}\text { Segmentos com mais } \\
\text { roubos a pedestres no } \\
\text { turno da tarde }(10)\end{array}$ & $3(37,5 \%)$ & $13(27 \%)$ & $16(30,8 \%)$ & $8(25,8 \%)$ & $3(37,5 \%)$ & $43(29 \%)$ \\
\hline $\begin{array}{l}\text { Segmentos com mais } \\
\text { roubos a pedestres no } \\
\text { turno da noite }(10)\end{array}$ & $3(37,5 \%)$ & $23(47,9 \%)$ & $14(26,9 \%)$ & $15(48,4 \%)$ & $0(0 \%)$ & $55(37,4 \%)$ \\
\hline $\begin{array}{l}\text { Segmentos com mais } \\
\text { roubos a pedestres na } \\
\text { madrugada (10) }\end{array}$ & $1(12,5 \%)$ & $6(12,5 \%)$ & $10(19,2 \%)$ & $6(19,3 \%)$ & $2(25 \%)$ & $25(17 \%)$ \\
\hline $\begin{array}{l}\text { Total de roubos a } \\
\text { pedestres }\end{array}$ & 8 & 48 & 52 & 31 & 8 & $147(100 \%)$ \\
\hline
\end{tabular}

Com relação aos demais atributos temporais, claramente, domingo é o dia com o menor número de ocorrências de roubos a pedestres (13), seguindo pela segunda-feira e terça-feira (18), com a maioria dos roubos a pedestres ocorrendo nas quartas-feiras (26), sábados (25), quintas-feiras (24) e sextasfeiras (23). Visivelmente, as maiores ocorrências de roubos a pedestres aconteceram em setembro (19) e em junho (18), e as menores ocorrências aconteceram em dezembro (8), seguido por janeiro (9), fevereiro (10) e maio, outubro e novembro (11).

As análises que se seguem tratam da quantidade de segmentos que se enquadra em cada categoria dos atributos físico-espaciais e configuracionais considerados. Assim, independentemente do turno do dia, a porcentagem de segmentos com comprimento acima de $150 \mathrm{~m}$ é claramente maior nos segmentos com mais roubos a pedestre, variando entre $60 \%$ (à tarde e durante a madrugada) e $40 \%$ (à noite), do que nos segmentos sem roubo a pedestre nos quatro turnos (13,33\%) (Tabela 2). Por sua vez, os valores de conectividade dos segmentos variam de 4 a 6 , tanto para os segmentos sem roubo a pedestre nos quatro turnos quanto para os segmentos com mais roubos a pedestres em cada um desses quatros turnos, com os percentuais em cada uma dessas cinco categorias de segmentos (para cada valor de conectividade) não apresentando variações superiores a 20\% (Tabela 2).

Considerando os valores de integração global dos 30 segmentos sem roubo a pedestre nos quatro turnos e dos segmentos com mais roubos a pedestres em cada um dos turnos (10 segmentos em cada turno em um total de 28, visto que 12 desses segmentos se repetem em diferentes turnos), observa-se que a percentagem de segmentos com os maiores valores de integração global é muito menor nos segmentos sem roubo a pedestre nos quatro turnos (20\%) do que nos segmentos com mais roubos a pedestres pela manhã (50\%), à tarde (40\%) e durante o turno da noite (60\%). O turno da madrugada foi desconsiderado nesta análise porque o movimento de pessoas e veículos é muito baixo ou inexistente na expressiva maioria ou totalidade dos segmentos na região central de Porto Alegre (Tabela 3). Ainda, 30\% dos 30 segmentos sem roubo a pedestre têm os menores valores de integração global, enquanto nenhum segmento com mais roubos a pedestres durante a manhã, tarde e noite apresenta tais valores. Portanto, o roubo a pedestre tende a ocorrer nos segmentos com maiores valores de integração global, o que também pode ser observado na comparação dos valores mais altos e mais baixos e das médias dos valores de integração global entre os grupos de segmentos sem roubo a pedestre e aqueles com mais roubos a pedestres durante os turnos da manhã, tarde e noite. Adicionalmente, o valor médio de integração global é claramente menor no grupo dos segmentos sem roubo a pedestre $(4.300,03)$ do que nos segmentos com mais roubos durante a manhã $(4.605,46)$, tarde $(4.578,94)$ e noite $(4.670,26)$ (Tabela 3$)$. 
Tabela 2 - Comprimento, conectividade e roubos a pedestres nos segmentos

\begin{tabular}{l|c|c|c|c|c}
\hline & $\begin{array}{c}\text { Segmentos } \\
\text { sem roubo a } \\
\text { pedestre nos } \\
\text { quatro } \\
\text { turnos (30) }\end{array}$ & $\begin{array}{c}\text { Segmentos } \\
\text { com mais } \\
\text { roubos a } \\
\text { pedestres pela } \\
\text { manhã (10) }\end{array}$ & $\begin{array}{c}\text { Segmentos } \\
\text { com mais } \\
\text { roubos a } \\
\text { pedestres à } \\
\text { tarde (10) }\end{array}$ & $\begin{array}{c}\text { Segmentos } \\
\text { com mais } \\
\text { roubos a } \\
\text { pedestres à } \\
\text { noite (10) }\end{array}$ & $\begin{array}{c}\text { Segmentos com } \\
\text { mais roubos a } \\
\text { pedestres na } \\
\text { madrugada (10 }\end{array}$ \\
\hline \multicolumn{5}{|c|}{ Comprimento do segmento } \\
\hline valor mais alto & $274,11 \mathrm{~m}$ & $347,46 \mathrm{~m}$ & $267,18 \mathrm{~m}$ & $347,46 \mathrm{~m}$ & $274,94 \mathrm{~m}$ \\
\hline valor mais baixo & $41,75 \mathrm{~m}$ & $53,17 \mathrm{~m}$ & $53,17 \mathrm{~m}$ & $76,51 \mathrm{~m}$ & $79,69 \mathrm{~m}$ \\
\hline até $50 \mathrm{~m}$ & $1(3,33 \%)$ & $0(0 \%)$ & $0(0 \%)$ & $0(0 \%)$ & $0(0 \%)$ \\
\hline $\begin{array}{l}\text { acima de } 50 \mathrm{~m} \text { e até } 100 \\
\mathrm{~m}\end{array}$ & $10(33,33 \%)$ & $2(20 \%)$ & $1(10 \%)$ & $3(30 \%)$ & $2(20 \%)$ \\
\hline $\begin{array}{l}\text { acima de } 100 \mathrm{~m} \text { e até } 150 \\
\mathrm{~m}\end{array}$ & $15(50 \%)$ & $3(30 \%)$ & $3(30 \%)$ & $3(30 \%)$ & $2(20 \%)$ \\
\hline acima de $150 \mathrm{~m}$ e até $200 \mathrm{~m}$ & $3(10 \%)$ & $2(20 \%)$ & $3(30 \%)$ & $3(30 \%)$ & $3(30 \%)$ \\
\hline acima de $200 \mathrm{~m}$ & $1(3,33 \%)$ & $3(30 \%)$ & $3(30 \%)$ & $1(10 \%)$ & $3(30 \%)$ \\
\hline \multicolumn{7}{|c|}{ Conectividade do segmento } & & 6 \\
\hline valor mais alto & 6 & 6 & 6 & 6 & 4 \\
\hline valor mais baixo & 4 & 4 & 4 & $5(50 \%)$ & $4(40 \%)$ \\
\hline valor de conectividade 4 & $10(33,33 \%)$ & $4(40 \%)$ & $4(40 \%)$ & $2(20 \%)$ & $3(30 \%)$ \\
\hline valor de conectividade 5 & $12(40 \%)$ & $4(40 \%)$ & $3(30 \%)$ & $3(30 \%)$ & $3(30 \%)$ \\
\hline valor de conectividade 6 & $8(26,67 \%)$ & $2(20 \%)$ & $3(30 \%)$ &
\end{tabular}

Tabela 3 - Valores de integração global e local e roubos a pedestres nos segmentos

\begin{tabular}{|c|c|c|c|c|c|}
\hline & $\begin{array}{l}\text { Segmentos sem } \\
\text { roubo a } \\
\text { pedestre nos } \\
\text { quatro turnos } \\
(30) \\
\end{array}$ & $\begin{array}{c}\text { Segmentos } \\
\text { com mais } \\
\text { roubos a } \\
\text { pedestres pela } \\
\text { manhã (10) } \\
\end{array}$ & $\begin{array}{l}\text { Segmentos } \\
\text { com mais } \\
\text { roubos a } \\
\text { pedestres à } \\
\text { tarde (10) } \\
\end{array}$ & $\begin{array}{c}\text { Segmentos com } \\
\text { mais roubos a } \\
\text { pedestres à } \\
\text { noite }(10)\end{array}$ & $\begin{array}{c}\text { Segmentos com } \\
\text { mais roubos a } \\
\text { pedestres na } \\
\text { madrugada } \\
(10) \\
\end{array}$ \\
\hline \multicolumn{6}{|c|}{ Integração global Rn (variando entre 3.714,87 e 4.979,00 em um grupo com 58 segmentos diferentes) } \\
\hline Valor mais alto & $4.763,85$ & $4.979,00$ & $4.979,00$ & $4.978,30$ & $4.978,30$ \\
\hline $\begin{array}{l}\text { Valor mais } \\
\text { baixo }\end{array}$ & $3.714,87$ & $4.170,55$ & $4.234,88$ & $4.225,41$ & $3.871,35$ \\
\hline Valor médio & $4.300,03$ & $4.605,46$ & $4.578,94$ & $4.670,26$ & $4.420,36$ \\
\hline $\begin{array}{c}\text { Valores altos } \\
(4.557,01- \\
4.979,00) \\
\end{array}$ & $6(20 \%)$ & $5(50 \%)$ & $4(40 \%)$ & $6(60 \%)$ & $3(30 \%)$ \\
\hline $\begin{array}{c}\text { Valores médios } \\
(4.136,01- \\
4.557,00) \\
\end{array}$ & $15(50 \%)$ & $5(50 \%)$ & $6(60 \%)$ & $4(40 \%)$ & $6(60 \%)$ \\
\hline $\begin{array}{c}\text { Valores baixos } \\
(3.714,00- \\
4.136,00) \\
\end{array}$ & $9(30 \%)$ & $0(0 \%)$ & $0(0 \%)$ & $0(0 \%)$ & $1(10 \%)$ \\
\hline \multicolumn{6}{|c|}{ Integração local R750 (variando entre 58,99 e 1.062,04 em um grupo com 58 segmentos diferentes) } \\
\hline Valor mais alto & $1.062,04$ & 666,20 & $1.059,89$ & $1.024,79$ & $1.059,89$ \\
\hline $\begin{array}{l}\text { Valor mais } \\
\text { baixo }\end{array}$ & 73,12 & 128,12 & 111,06 & 165,63 & 58,99 \\
\hline Valor médio & 309,70 & 324,08 & 538,73 & 530,56 & 281,48 \\
\hline $\begin{array}{c}\text { Valores altos } \\
(728,01- \\
1.063,00) \\
\end{array}$ & $2(6,67 \%)$ & $0(0 \%)$ & 3 (30\%) & 3 (30\%) & $1(10 \%)$ \\
\hline $\begin{array}{c}\text { Valores médios } \\
(394,01- \\
728,00)\end{array}$ & $5(16,67 \%)$ & 3 (30\%) & $3(30 \%)$ & 2 (20\%) & $0(0 \%)$ \\
\hline $\begin{array}{l}\text { Valores baixos } \\
(58,00-394,00)\end{array}$ & 23 (76,67\%) & 7 (70\%) & $4(40 \%)$ & $5(50 \%)$ & $9(90 \%)$ \\
\hline
\end{tabular}

Nota: são 58 segmentos diferentes (e não 70) porque 12 segmentos estão entre aqueles com mais roubos a pedestres em mais de um turno. 
Em relação à integração local, a clara maioria dos segmentos sem roubo a pedestre $(76,67 \%)$ e com mais roubos a pedestres no turno da manhã (70\%) possui baixos valores de integração local. Por outro lado, os percentuais de segmentos com mais roubos a pedestres durante a tarde e durante a noite estão mais distribuídos, com valores baixos (respectivamente $40 \%$ e $50 \%$ ), médios (respectivamente $30 \%$ e $20 \%$ ) e altos de integração local (respectivamente $30 \%$ e $30 \%$ ). Ainda, o valor médio de integração local é menor no grupo dos segmentos sem roubo a pedestre $(309,70)$ do que nos segmentos com mais roubos durante a manhã $(324,08)$, e nitidamente menor do que naqueles segmentos com mais roubos nos turnos da tarde $(538,73)$ e da noite $(530,56)$ (Tabela 3). Logo, não há clara indicação do efeito dos valores de integração local na ocorrência de roubos a pedestres, embora essas ocorrências nos turnos da tarde e da noite possam ser facilitadas em segmentos com valores mais altos de integração local.

A análise da escolha global mostra que quase a totalidade dos segmentos sem roubo a pedestre $(93,33 \%)$ e que a maioria dos segmentos com mais roubos a pedestres pela manhã (60\%), tarde (70\%) e noite $(60 \%)$ possuem os menores valores de escolha global. Contudo, o valor médio de escolha global é muito menor nos segmentos sem roubo a pedestre do que nos segmentos com mais roubos a pedestres nos turnos da manhã, tarde e noite (Tabela 4). O turno da madrugada foi novamente desconsiderado em função do fato de o movimento de pessoas e veículos ser muito baixo ou inexistente nos segmentos considerados. Portanto, embora não existam claras evidências acerca do efeito da escolha global sobre o roubo a pedestre, este parece ser facilitado em segmentos com valores de escolha global mais altos. Por sua vez, a análise da escolha local revela que a totalidade ou a clara maioria dos segmentos, tanto aqueles com mais roubos a pedestres nos turnos da manhã, tarde e noite quanto aqueles sem roubo a pedestre, possuem os menores valores de escolha local (Tabela 4). Contudo, os roubos a pedestres no turno da tarde aumentam à medida que os valores de escolha local aumentam, como revelado pela correlação positiva (correlação de Spearman, coef. $=0,392$, sig. $=0,32$ ) entre a quantidade de roubos no turno da tarde em cada segmento e os valores de escolha local dos segmentos. Adicionalmente, o valor médio de escolha local nos segmentos sem roubo a pedestre é bem menor do que nos segmentos com mais roubos a pedestres no turno da manhã e, principalmente, nos turnos da tarde e da noite.

A análise das taxas de conexão física revelou que $56,67 \%$ dos segmentos sem roubo a pedestre têm taxas de conexão física altas ou muito altas, enquanto a totalidade dos segmentos com mais roubos a pedestres nos turnos da manhã e da tarde e $90 \%$ dos segmentos com mais roubos a pedestres durante a noite têm taxas de conexão física baixas ou muito baixas, desconsiderando-se o turno da madrugada devido ao reduzido ou inexistente acesso às edificações a partir das ruas nesse período (Tabela 5). Portanto, em qualquer um dos três turnos considerados, a maioria dos roubos a pedestres ocorre em segmentos com taxa de conexão física igual ou inferior a 0,038 (um acesso a uma edificação a cada $26 \mathrm{~m}$ ou em intervalos maiores, considerando uma distribuição uniforme dos acessos pelos dois lados do segmento), e a totalidade ou quase a totalidade desse tipo de crime ocorre nos segmentos com taxas de conexão física iguais ou inferiores a 0,077 , o que significa um acesso a uma edificação a cada $13 \mathrm{~m}$ ou em intervalos maiores, no caso de tais acessos estarem uniformemente distribuídos pelos dois lados do segmento. Adicionalmente, a taxa média de conexão física nos segmentos sem roubo a pedestre $(0,118)$ é muito mais alta do que nos segmentos com roubos a pedestres nos turnos da manhã $(0,018)$, tarde $(0,020)$ e noite $(0,037)$ (Tabela 5$)$. Logo, a quantidade de conexões físicas entre as edificações e a rua é um forte indicador do potencial da quantidade de roubos a pedestres no segmento. Esses resultados revelam o impacto do número de acessos a edificações sobre a ocorrência de roubos a pedestres nos segmentos, mas não informam acerca da distribuição mais eficaz de tais acessos em ambos os lados do segmento para melhor inibir o assaltante a cometer o crime, o que não é parte dos objetivos desta pesquisa. 
Tabela 4 - Valores de escolha global e local e roubos a pedestres nos segmentos

\begin{tabular}{|c|c|c|c|c|c|}
\hline & $\begin{array}{c}\text { Segmentos } \\
\text { sem roubo a } \\
\text { pedestre nos } \\
\text { quatro turnos } \\
\text { (30) }\end{array}$ & $\begin{array}{c}\text { Segmentos } \\
\text { com mais } \\
\text { roubos a } \\
\text { pedestres pela } \\
\text { manhã (10) }\end{array}$ & $\begin{array}{l}\text { Segmentos } \\
\text { com mais } \\
\text { roubos a } \\
\text { pedestres à } \\
\text { tarde (10) }\end{array}$ & $\begin{array}{l}\text { Segmentos } \\
\text { com mais } \\
\text { roubos a } \\
\text { pedestres à } \\
\text { noite (10) }\end{array}$ & $\begin{array}{c}\text { Segmentos } \\
\text { com mais } \\
\text { roubos a } \\
\text { pedestres na } \\
\text { madrugada } \\
(10)\end{array}$ \\
\hline \multicolumn{6}{|c|}{ Escolha global Rn (variando entre 12,00 e 41.425.612,00 em um grupo de 58 segmentos diferentes) } \\
\hline Valor mais alto & $19.889 .318,00$ & $41.425 .612,00$ & $37.100 .596,00$ & $38.394 .912,00$ & 38.394.912,00 \\
\hline $\begin{array}{l}\text { Valor mais } \\
\text { baixo }\end{array}$ & 12,00 & 21113,00 & 76790,00 & 133599,00 & 64,00 \\
\hline Valor médio & $1.876 .443,43$ & $15.413 .733,30$ & $11.891 .189,40$ & 13.497.637,70 & $5.312 .487,30$ \\
\hline $\begin{array}{c}\text { Valores } \\
\text { máximos } \\
(27.617 .078,01- \\
41.425 .612,00)\end{array}$ & $0(0 \%)$ & $4(40 \%)$ & $3(30 \%)$ & $3(30 \%)$ & $1(10 \%)$ \\
\hline $\begin{array}{c}\text { Valores médios } \\
(13.808 .545,01- \\
27.617 .078,00) \\
\end{array}$ & $2(6,67 \%)$ & $0(0 \%)$ & $0(0 \%)$ & $1(10 \%)$ & $0(0 \%)$ \\
\hline $\begin{array}{c}\text { Valores } \\
\text { mínimos } \\
(12,00- \\
13.808 .545,00)\end{array}$ & $28(93,33 \%)$ & $6(60 \%)$ & $7(70 \%)$ & $6(60 \%)$ & $9(90 \%)$ \\
\hline \multicolumn{6}{|c|}{ Escolha local R750 (variando entre 23,00 e 115.357,00 em um grupo de 58 segmentos diferentes) } \\
\hline Valor mais alto & $67.565,00$ & $28.841,00$ & $115.357,00$ & $83.037,00$ & $115.357,00$ \\
\hline $\begin{array}{l}\text { Valor mais } \\
\text { baixo }\end{array}$ & 23,00 & 949,00 & $1.109,00$ & $1.489,00$ & 118,00 \\
\hline Valor médio & $5.184,97$ & $8.740,20$ & $25.568,50$ & $21.689,20$ & $13.546,30$ \\
\hline $\begin{array}{c}\text { Valores } \\
\text { máximos } \\
(76.912,01- \\
115.357,00)\end{array}$ & $0(0 \%)$ & $0(0 \%)$ & $1(10 \%)$ & $1(10 \%)$ & $1(10 \%)$ \\
\hline $\begin{array}{c}\text { Valores médios } \\
(38.467,01- \\
76.912,00) \\
\end{array}$ & $1(3,33 \%)$ & $0(0 \%)$ & $0(0 \%)$ & $1(10 \%)$ & $0(0 \%)$ \\
\hline $\begin{array}{c}\text { Valores } \\
\text { mínimos } \\
(23,00- \\
38.467,00)\end{array}$ & 29 (96,67\%) & 10 (100\%) & 9 (90\%) & $8(80 \%)$ & 9 (90\%) \\
\hline
\end{tabular}


Tabela 5 - Taxas de conexão física e visual e roubos a pedestres nos segmentos

\begin{tabular}{|c|c|c|c|c|c|}
\hline & $\begin{array}{c}\text { Segmentos } \\
\text { sem roubo a } \\
\text { pedestre nos } \\
\text { quatro turnos } \\
\text { (30) }\end{array}$ & $\begin{array}{c}\text { Segmentos } \\
\text { com mais } \\
\text { roubos a } \\
\text { pedestres pela } \\
\text { manhã (10) }\end{array}$ & $\begin{array}{l}\text { Segmentos } \\
\text { com mais } \\
\text { roubos a } \\
\text { pedestres à } \\
\text { tarde (10) }\end{array}$ & $\begin{array}{c}\text { Segmentos } \\
\text { com mais } \\
\text { roubos a } \\
\text { pedestres à } \\
\text { noite (10) }\end{array}$ & $\begin{array}{c}\text { Segmentos } \\
\text { com mais } \\
\text { roubos a } \\
\text { pedestres na } \\
\text { madrugada } \\
\text { (10) }\end{array}$ \\
\hline \multicolumn{6}{|c|}{ Taxa de conexão física (variando entre 0,000 e 0,193 em um grupo com 58 segmentos diferentes) } \\
\hline $\begin{array}{l}\text { Taxa mais } \\
\text { alta }\end{array}$ & 0,193 & 0,058 & 0,057 & 0,125 & 0,165 \\
\hline $\begin{array}{l}\text { Taxa mais } \\
\text { baixa }\end{array}$ & 0,045 & 0,000 & 0,000 & 0,001 & 0,000 \\
\hline Taxa média & 0,118 & 0,018 & 0,020 & 0,037 & 0,100 \\
\hline $\begin{array}{c}\text { Taxas muito } \\
\text { altas } \\
(0,155-0,193)\end{array}$ & $6(20 \%)$ & $0(0 \%)$ & $0(0 \%)$ & $0(0 \%)$ & $1(10 \%)$ \\
\hline $\begin{array}{c}\text { Taxas altas } \\
(0,116-0,154)\end{array}$ & $11(36,67 \%)$ & $0(0 \%)$ & $0(0 \%)$ & $1(10 \%)$ & $3(30 \%)$ \\
\hline $\begin{array}{c}\text { Taxas médias } \\
(0,078-0,115)\end{array}$ & 7 (23,33\%) & $0(0 \%)$ & $0(0 \%)$ & $0(0 \%)$ & $4(40 \%)$ \\
\hline $\begin{array}{l}\text { Taxas baixas } \\
(0,039-0,077)\end{array}$ & $6(20 \%)$ & $2(20 \%)$ & $2(20 \%)$ & $3(30 \%)$ & $0(0 \%)$ \\
\hline $\begin{array}{c}\text { Taxas muito } \\
\text { baixas } \\
(0,000-0,038)\end{array}$ & $0(0 \%)$ & $8(80 \%)$ & $8(80 \%)$ & $6(60 \%)$ & $2(20 \%)$ \\
\hline \multicolumn{6}{|c|}{ Taxa de conexão visual (variando entre 0,000 e 0,486 em um grupo de 58 segmentos diferentes) } \\
\hline $\begin{array}{l}\text { Taxa mais } \\
\text { alta }\end{array}$ & 0,486 & 0,192 & 0,041 & 0,102 & 0,201 \\
\hline $\begin{array}{l}\text { Taxa mais } \\
\text { baixa }\end{array}$ & 0,074 & 0,000 & 0,000 & 0,000 & 0,000 \\
\hline Taxa média & 0,195 & 0,030 & 0,020 & 0,041 & 0,110 \\
\hline $\begin{array}{c}\text { Taxas muito } \\
\text { altas } \\
(0,389-0,486)\end{array}$ & $1(3,33 \%)$ & $0(0 \%)$ & $0(0 \%)$ & $0(0 \%)$ & $0(0 \%)$ \\
\hline $\begin{array}{c}\text { Taxas altas } \\
(0,292-0,388)\end{array}$ & $3(10 \%)$ & $0(0 \%)$ & $0(0 \%)$ & $0(0 \%)$ & $0(0 \%)$ \\
\hline $\begin{array}{c}\text { Taxas médias } \\
(0,195-0,291)\end{array}$ & $9(30 \%)$ & $0(0 \%)$ & $0(0 \%)$ & $0(0 \%)$ & $1(10 \%)$ \\
\hline $\begin{array}{l}\text { Taxas baixas } \\
(0,098-0,194)\end{array}$ & $12(40 \%)$ & $1(10 \%)$ & $0(0 \%)$ & $1(10 \%)$ & $6(60 \%)$ \\
\hline $\begin{array}{c}\text { Taxas muito } \\
\text { baixas } \\
(0,000-0,097)\end{array}$ & $5(16,67 \%)$ & $9(90 \%)$ & 10 (100\%) & $9(90 \%)$ & $3(30 \%)$ \\
\hline
\end{tabular}

Nota: exemplificando, uma taxa de conexão física de 0,193 (56 acessos/ 289,62 m) significa que há um acesso a uma edificação a cada $5,17 \mathrm{~m}(289,62 \mathrm{~m} / 56$ acessos) no comprimento total dos dois lados do segmento (289,62 m); uma taxa de conexão visual de 0,486 significa que $49 \%$ do comprimento total dos dois lados do segmento apresentam conexão visual entre as edificações e os espaços abertos públicos das ruas. 
Com relação às conexões visuais entre as edificações e os espaços abertos públicos, a maioria $(56,67 \%)$ dos segmentos sem roubo a pedestre possui taxas de conexão visual baixas ou muito baixas (Tabela 5), enquanto a totalidade dos segmentos com mais roubos a pedestres pela manhã, tarde e noite tem taxas de conexão visual baixas ou muito baixas. O turno da madrugada não foi considerado devido à inexistência ou quase inexistência de supervisão visual das ruas por parte de pessoas nas edificações. Os roubos a pedestres nos três turnos considerados ocorrem em segmentos onde, no máximo, 19\% (taxa de 0,194) do comprimento total (dois lados do segmento) são visualmente conectados. Além disso, a totalidade de roubos a pedestres durante a tarde e quase a totalidade (90\%) durante os turnos da manhã e da noite ocorreram em segmentos nos quais as conexões visuais entre as edificações e a rua não é maior do que $10 \%$ (taxa de 0,097 ) do total do comprimento do segmento (ambos os lados). Ainda, a taxa média de conexão visual nos segmentos sem roubo a pedestre $(0,195)$ é muito mais alta do que nos segmentos com roubos a pedestres nos turnos da manhã $(0,030)$, tarde $(0,020)$ e noite $(0,041)$ (Tabela 5). Logo, as taxas de conexão visual entre as edificações e os espaços públicos das ruas aparecem como um importante indicador do potencial de roubos a pedestres nos turnos da manhã, da tarde e da noite. Adicionalmente, foi encontrada uma correlação negativa (correlação de Spearman, coef. $=-0,426$, sig. $=0,019$ ) entre roubo a pedestre no turno da tarde e taxas de conexão visual, confirmando que o roubo a pedestre aumenta à medida que essas taxas diminuem. Contudo, não faz parte desses resultados e dos objetivos deste estudo a consideração da distribuição mais eficaz das conexões visuais ao longo de ambos os lados do segmento para melhor prevenir o roubo a pedestre.

A análise das taxas de porta de garagem mostra que o número dessas portas em um segmento não teve efeito sobre a ocorrência de roubos a pedestres em nenhum dos três períodos considerados. Por sua vez, a totalidade dos roubos a pedestres durante a noite e quase a totalidade durante o turno da madrugada (80\%) ocorreram em segmentos com baixas $(0,044-0,069)$ ou muito baixas $(0,017-$ 0,043 ) taxas de postes de luz, e nenhum roubo a pedestre no turno da madrugada ocorreu nos segmentos com taxas de postes de luz muito altas ou altas. Com relação às barreiras físicas e visuais, a totalidade de segmentos com mais roubos a pedestres pela manhã e quase a totalidade durante a tarde (90\%) e a noite (80\%) têm taxas de barreiras física e visual muito baixas $(0,000-0,100)$, o que indica que essas quantidades de barreiras nas ruas não contribuíram para tais ocorrências nesses três turnos, desconsiderando-se o turno da madrugada, quando essas barreiras tendem a não atuar no bloqueio da supervisão visual das ruas pelos usuários das edificações.

A análise das taxas das edificações com uso misto revela que a clara maioria dos segmentos com mais roubos a pedestres pela manhã (80\%), tarde (80\%) e noite (70\%) tem taxas de uso misto muito baixas (0,000-0,009). Além disso, em nenhum dos três turnos do dia ocorreu roubo a pedestre em segmentos com taxas muito altas $(0,037-0,046)$, e quase não ocorreu em segmentos com taxas altas $(0,028-0,036)$ de uso misto. Adicionalmente, $43,34 \%$ dos segmentos sem roubo a pedestre têm taxas de uso misto altas ou muito altas, enquanto somente $16,6 \%$ desses segmentos têm taxas de uso misto muito baixas $(0,000-0,009)$. Consequentemente, a existência de edificações com uso misto (residencial, comercial e serviços) em uma rua tende a ter um efeito positivo na redução do roubo a pedestre, o que é também evidenciado pelo fato de a taxa média de edificações com uso misto ser bem mais alta nos segmentos sem roubo a pedestre $(0,025)$ do que nos segmentos com mais roubos a pedestres nos turnos da manhã $(0,007)$, tarde $(0,007)$ e noite $(0,010)$ (Tabela 6$)$.

A análise da existência de edificações com uso residencial mostra que todos os segmentos com mais roubos a pedestres nos turnos da manhã e da tarde e $90 \%$ dos segmentos com mais roubos a pedestres durante a noite têm taxas de edificações com uso residencial muito baixas $(0,000-0,020)$, enquanto essas taxas existem em um percentual bem menor $(53,33 \%)$ nos segmentos sem roubo a pedestre. Ainda, a taxa média de edificações com uso residencial nos segmentos sem roubo a pedestre $(0,022)$ é muito mais alta do que nos segmentos com mais roubos a pedestres nos turnos da manhã $(0,002)$, tarde $(0,001)$ e noite $(0,005)$ (Tabela 7$)$. Portanto, o roubo a pedestre nesses turnos do dia tende a ser facilitado em ruas com taxas muito baixas de edificações com uso residencial. Isso é sustentado pelo fato de que os roubos a pedestres nas manhãs e tardes aumentam à medida que as taxas de edificações com uso residencial diminuem, conforme as correlações negativas entre roubo a pedestre em cada um desses dois turnos e a taxa de edificações com uso residencial (respectivamente correlação de Spearman, coef. = -0,422, sig. = 0,020 , e correlação de Spearman, coef. $=-0,493$, sig. $=0,006)$.

Quanto à existência de edificações de uso comercial/serviço no segmento, $80 \%$ dos roubos a pedestres no turno da manhã, $100 \%$ à tarde e $70 \%$ à noite ocorreram em segmentos com taxas de edificações de uso comercial/serviço muito baixas $(0,000-0,016 ; 0,016=1,6 / 100 \mathrm{~m}=1,6$ acessos $\mathrm{a}$ 
tais edificações em 100 m). Portanto, a ocorrência de roubos a pedestres tende a se concentrar nos segmentos onde as taxas de edificações de uso comercial/serviço são muito baixas, isto é, onde existe acesso a uma edificação de uso comercial/serviço a cada 62,5 m $(100 / 1,6)$ ou em intervalos maiores. Ainda, a taxa média de edificações com usos comercial e de serviço nos segmentos sem roubo a pedestre $(0,026)$ é bem mais alta do que nos segmentos com roubos a pedestres nos turnos da manhã $(0,008)$, tarde $(0,006)$ e noite $(0,013)$ (Tabela 8).

Tabela 6 - Taxas de edificações com uso misto e roubos a pedestres nos segmentos

\begin{tabular}{l|c|c|c|c|c}
\hline & $\begin{array}{c}\text { Segmentos } \\
\text { sem roubo a } \\
\text { pedestre nos } \\
\text { quatro } \\
\text { turnos (30) }\end{array}$ & $\begin{array}{c}\text { Segmentos } \\
\text { com mais } \\
\text { roubos a } \\
\text { pedestres pela } \\
\text { manhã (10) }\end{array}$ & $\begin{array}{c}\text { Segmentos } \\
\text { com mais } \\
\text { roubos a } \\
\text { pedestres à } \\
\text { tarde (10) }\end{array}$ & $\begin{array}{c}\text { Segmentos } \\
\text { com mais } \\
\text { roubos a } \\
\text { pedestres à } \\
\text { noite (10) }\end{array}$ & $\begin{array}{c}\text { Segmentos } \\
\text { com mais } \\
\text { roubos a } \\
\text { pedestres na } \\
\text { madrugada } \\
\text { (10) }\end{array}$ \\
\hline Taxas de edificações com uso misto (variando de 0,000 a 0,046 em um grupo com 58 segmentos diferentes) \\
\hline Taxa mais alta & 0,046 & 0,031 & 0,026 & 0,034 & 0,044 \\
\hline Taxa mais baixa & 0,000 & 0,000 & 0,000 & 0,000 & 0,000 \\
\hline Taxa média & 0,025 & 0,007 & 0,007 & 0,010 & 0,017 \\
\hline $\begin{array}{l}\text { Taxas muito } \\
\text { altas (0,037- } \\
0,046)\end{array}$ & $11(36,67 \%)$ & $0(0 \%)$ & $0(0 \%)$ & $0(0 \%)$ & $1(10 \%)$ \\
\hline $\begin{array}{l}\text { Taxas altas } \\
(0,028-0,036)\end{array}$ & $2(6,67 \%)$ & $1(10 \%)$ & $0(0 \%)$ & $1(10 \%)$ & $3(30 \%)$ \\
\hline $\begin{array}{l}\text { Taxas médias } \\
(0,019-0,027)\end{array}$ & $5(16,67 \%)$ & $1(10 \%)$ & $2(20 \%)$ & $2(20 \%)$ & $0(0 \%)$ \\
\hline $\begin{array}{l}\text { Taxas baixas } \\
(0,010-0,018)\end{array}$ & $7(23,33 \%)$ & $0(0 \%)$ & $0(0 \%)$ & $0(0 \%)$ & $0(0 \%)$ \\
\hline $\begin{array}{l}\text { Taxas muito } \\
\text { baixas }(0,000- \\
0,009)\end{array}$ & $5(16,67 \%)$ & $8(80 \%)$ & $8(80 \%)$ & $7(70 \%)$ & $6(60 \%)$ \\
\hline
\end{tabular}

Tabela 7 - Taxas de edificações com uso residencial e roubos a pedestres nos segmentos

\begin{tabular}{l|c|c|c|c|c}
\hline & $\begin{array}{c}\text { Segmentos sem } \\
\text { roubo a } \\
\text { pedestre nos } \\
\text { quatro turnos } \\
\mathbf{( 3 0 )}\end{array}$ & $\begin{array}{c}\text { Segmentos } \\
\text { com mais } \\
\text { roubos a } \\
\text { pedestres } \\
\text { pela manhã } \\
\mathbf{( 1 0 )}\end{array}$ & $\begin{array}{c}\text { Segmentos } \\
\text { com mais } \\
\text { roubos a } \\
\text { pedestres à } \\
\text { tarde (10) }\end{array}$ & $\begin{array}{c}\text { Segmentos } \\
\text { com mais } \\
\text { roubos a } \\
\text { pedestres à } \\
\text { noite (10) }\end{array}$ & $\begin{array}{c}\text { Segmentos } \\
\text { com mais } \\
\text { roubos a } \\
\text { pedestres na } \\
\text { madrugada } \\
(\mathbf{1 0})\end{array}$ \\
\hline \multicolumn{1}{c|}{ Taxas de edificações com uso residencial (variando de 0,000 a 0,104 em um grupo com 58 segmentos } \\
diferentes)
\end{tabular}


Tabela 8 - Taxas de edificações com usos comercial e de serviço e roubos a pedestres nos segmentos

\begin{tabular}{c|c|c|c|c|c}
\hline & $\begin{array}{c}\text { Segmentos } \\
\text { sem roubo a } \\
\text { pedestre nos } \\
\text { quatro } \\
\text { turnos (30) }\end{array}$ & $\begin{array}{c}\text { Segmentos } \\
\text { com mais } \\
\text { roubos a } \\
\text { pedestres } \\
\text { pela manhã } \\
\mathbf{( 1 0 )}\end{array}$ & $\begin{array}{c}\text { Segmentos } \\
\text { com mais } \\
\text { roubos a } \\
\text { pedestres à } \\
\text { tarde (10) }\end{array}$ & $\begin{array}{c}\text { Segmentos } \\
\text { com mais } \\
\text { roubos a } \\
\text { pedestres à } \\
\text { noite (10) }\end{array}$ & $\begin{array}{c}\text { Segmentos } \\
\text { com mais } \\
\text { roubos a } \\
\text { pedestres na } \\
\text { madrugada } \\
(\mathbf{1 0})\end{array}$ \\
\hline Taxas de edificações com usos comercial e de serviço (variando de 0,000 a 0,084 em um grupo com 58 \\
segmentos diferentes)
\end{tabular}

Com relação à existência de edificações com atividades residenciais nos pavimentos térreos voltadas para a rua, $100 \%$ dos segmentos com mais roubos a pedestres em cada um dos quatro turnos têm taxas de atividade residencial no térreo muito baixas $(0,000-0,023 ; 0,023=2,3 / 100 \mathrm{~m}=2,3$ acessos a tais edificações em $100 \mathrm{~m}$ ), o que significa acesso a uma atividade residencial no térreo de uma edificação a cada 43,5 m (100/2,3) ou em intervalos maiores (Tabela 9). Portanto, a existência de atividades residenciais nos pavimentos térreos voltados para a rua em intervalos menores do que 43,5 m apresenta o potencial de desencorajar as ocorrências de roubos a pedestres. Isso é corroborado pela correlação negativa (correlação de Spearman, coef. $=-0,617$, sig. $=0,000$ ) entre roubo a pedestre no turno da tarde e a taxa de atividade residencial no térreo durante a tarde. Ainda, a taxa de atividade residencial no pavimento térreo é claramente superior nos segmentos sem roubo a pedestre $(0,014)$ em comparação às taxas nos segmentos com mais roubos a pedestres nos turnos da manhã $(0,001)$, tarde $(0,000)$ e noite $(0,000)$ (Tabela 9).

Sobre a existência de atividades de serviços nos pavimentos térreos voltados para a rua, 100\% dos segmentos com mais roubos a pedestres em qualquer turno têm taxas baixas $(0,000-0,010)$ de tais atividades, o que significa acesso a um térreo com atividade de serviço a cada $100 \mathrm{~m}$ ou mais. Portanto, a existência de atividade de serviço no pavimento térreo em intervalos inferiores a $100 \mathrm{~m}$ em uma rua apresenta o potencial de reduzir a ocorrência de roubo a pedestre. Isso é sustentado pela correlação negativa (correlação de Spearman, coef. $=-0,427$, sig. $=0,019$ ) entre roubo a pedestre no turno da tarde e a taxa de atividades de serviço no térreo durante a tarde. Adicionalmente, as taxas médias de atividades de serviço nos pavimentos térreos voltados para a rua são mais altas nos segmentos sem roubo a pedestre do que nos segmentos com mais roubos a pedestres nos turnos da manhã (respectivamente 0,008 e 0,002) e da tarde (respectivamente 0,009 e 0,002 ), sendo iguais no turno da noite (respectivamente 0,003 e 0,003), enquanto os valores mais altos das taxas de atividades de serviços nos térreos estão, em qualquer um desses três turnos, nos segmentos sem roubo a pedestre (Tabela 10). Por outro lado, foi encontrada uma correlação positiva (Spearman, coef. $=0,447$, sig. $=0,013$ ) entre roubo a pedestre no turno da noite e a taxa de atividades de serviço no térreo durante a noite. 
Tabela 9 - Taxas de uso residencial nos pavimentos térreos e roubos a pedestres nos segmentos

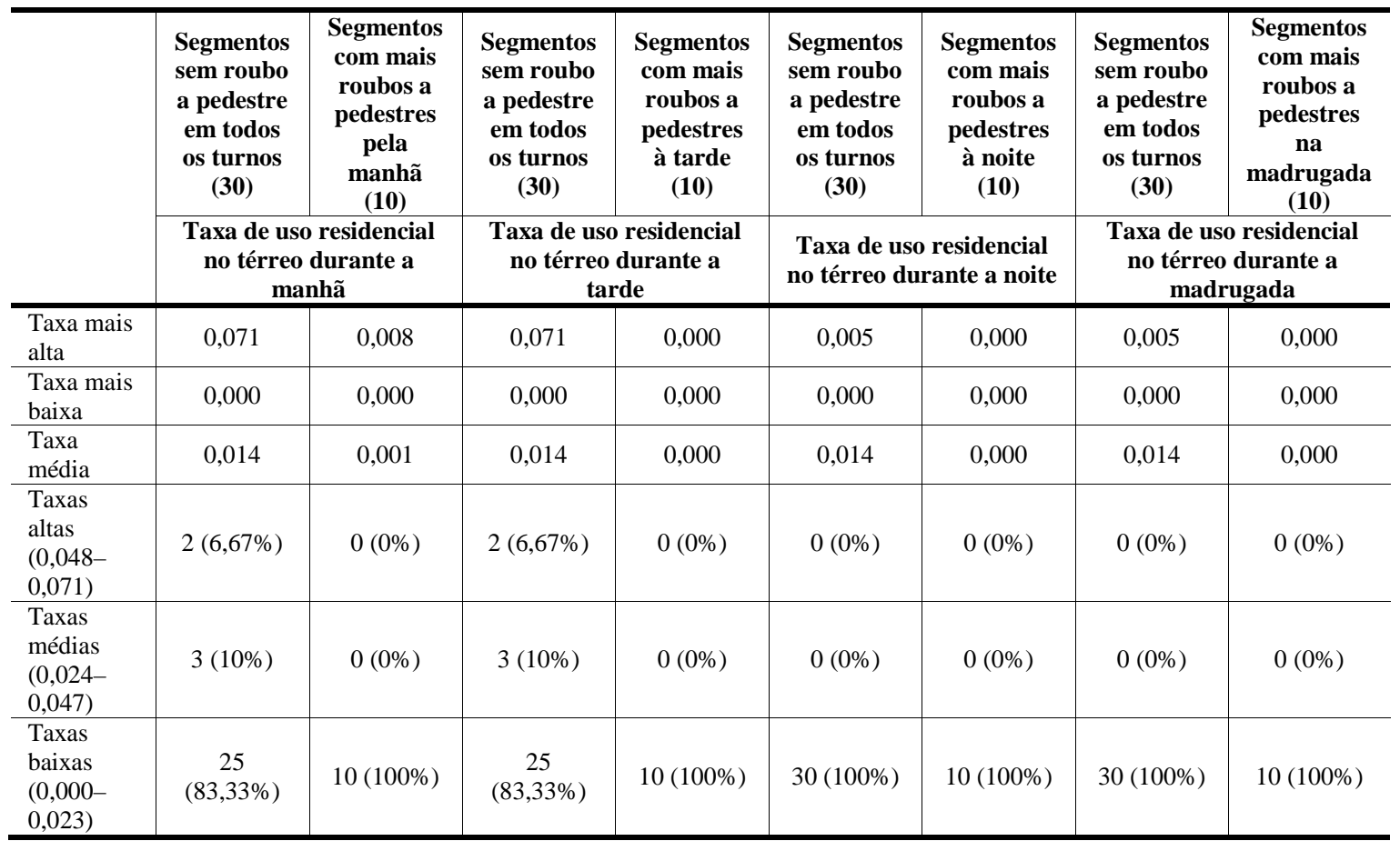

Nota: as taxas de uso residencial nos pavimentos térreos variam de 0,000 a 0,071 em um grupo com 58 segmentos diferentes.

Tabela 10 - Taxas de atividade de serviço nos pavimentos térreos e roubos a pedestres nos segmentos

\begin{tabular}{|c|c|c|c|c|c|c|c|c|}
\hline & $\begin{array}{c}\text { Segmentos } \\
\text { sem roubo } \\
\text { a pedestre } \\
\text { em } \\
\text { qualquer } \\
\text { um dos } \\
\text { turnos (30) }\end{array}$ & $\begin{array}{c}\text { Segmentos } \\
\text { com mais } \\
\text { roubos a } \\
\text { pedestres } \\
\text { no turno } \\
\text { da manhã } \\
(10)\end{array}$ & $\begin{array}{c}\text { Segmentos } \\
\text { sem roubo } \\
\text { a pedestre } \\
\text { em } \\
\text { qualquer } \\
\text { um dos } \\
\text { turnos (30) }\end{array}$ & $\begin{array}{c}\text { Segmentos } \\
\text { com mais } \\
\text { roubos a } \\
\text { pedestres } \\
\text { no turno } \\
\text { da tarde } \\
(10)\end{array}$ & $\begin{array}{c}\text { Segmentos } \\
\text { sem roubo } \\
\text { a pedestre } \\
\text { em } \\
\text { qualquer } \\
\text { um dos } \\
\text { turnos (30) }\end{array}$ & $\begin{array}{c}\text { Segmentos } \\
\text { com mais } \\
\text { roubos a } \\
\text { pedestres } \\
\text { no turno } \\
\text { da noite } \\
(10)\end{array}$ & $\begin{array}{c}\text { Segmentos } \\
\text { sem roubo } \\
\text { a pedestre } \\
\text { em } \\
\text { qualquer } \\
\text { um dos } \\
\text { turnos (30) }\end{array}$ & $\begin{array}{c}\text { Segmentos } \\
\text { com mais } \\
\text { roubos a } \\
\text { pedestres } \\
\text { no turno da } \\
\text { madrugada } \\
(10)\end{array}$ \\
\hline & \multicolumn{2}{|c|}{$\begin{array}{l}\text { Taxa de atividade de } \\
\text { serviço no térreo } \\
\text { durante a manhã }\end{array}$} & \multicolumn{2}{|c|}{$\begin{array}{c}\text { Taxa de atividade de } \\
\text { serviço no térreo durante } \\
\text { a tarde }\end{array}$} & \multicolumn{2}{|c|}{$\begin{array}{c}\text { Taxa de atividade de } \\
\text { serviço no térreo durante } \\
\text { a noite }\end{array}$} & \multicolumn{2}{|c|}{$\begin{array}{c}\text { Taxa de atividade de } \\
\text { serviço no térreo durante } \\
\text { a madrugada }\end{array}$} \\
\hline $\begin{array}{l}\text { Taxa } \\
\text { mais alta }\end{array}$ & 0,031 & 0,008 & 0,031 & 0,008 & 0,019 & 0,008 & 0,006 & 0,006 \\
\hline $\begin{array}{l}\text { Taxa } \\
\text { mais } \\
\text { baixa }\end{array}$ & 0,000 & 0,000 & 0,000 & 0,000 & 0,000 & 0,000 & 0,000 & 0,000 \\
\hline $\begin{array}{l}\text { Taxas } \\
\text { médias } \\
(0,011- \\
0,020)\end{array}$ & $9(30 \%)$ & $0(0 \%)$ & $\begin{array}{c}10 \\
(33,33 \%)\end{array}$ & $0(0 \%)$ & $3(10 \%)$ & $0(0 \%)$ & $0(0 \%)$ & $0(0 \%)$ \\
\hline $\begin{array}{l}\text { Taxas } \\
\text { baixas } \\
(0,00- \\
0,010)\end{array}$ & $\begin{array}{c}20 \\
(66,67 \%)\end{array}$ & 10 (100\%) & $\begin{array}{c}19 \\
(63,34 \%)\end{array}$ & 10 (100\%) & 27 (90\%) & 10 (100\%) & 30 (100\%) & 10 (100\%) \\
\hline
\end{tabular}

Nota: as taxas de atividade de serviço nos pavimentos térreos variam de 0,000 a 0,031 em um grupo com 58 segmentos diferentes; as atividades de serviços nos pavimentos térreos podem variar conforme o turno. 
A análise acerca da existência de atividades comerciais nos pavimentos térreos voltados para a rua revela que $100 \%$ dos segmentos com mais roubos a pedestres em qualquer um dos turnos têm taxas baixas $(0,000-0,041)$ de atividades comerciais nos térreos, o que significa acesso a um térreo com atividade comercial a cada $24,4 \mathrm{~m}$ ou em intervalos maiores. Por sua vez, 20\% (6) dos segmentos sem roubo a pedestre apresentam taxas médias de atividades comerciais nos térreos durante a manhã, enquanto 33,33\% (10) apresentam taxas médias, e $20 \%$ (6) apresentam altas taxas de atividades comerciais nos térreos durante a tarde. Adicionalmente, as taxas médias de atividades comerciais nos térreos são bem mais altas nos segmentos sem roubo a pedestre do que nos segmentos com mais roubos a pedestres nos turnos da manhã (respectivamente 0,024 e 0,005), tarde (respectivamente 0,046 e 0,004) e noite (respectivamente 0,009 e 0,002), relações estas que se mantêm quando se observam os valores mais altos das taxas de atividades comerciais nos térreos (Tabela 11). Consequentemente, a existência de atividades comerciais nos pavimentos térreos voltados para a rua, principalmente em intervalos de até $24 \mathrm{~m}$, tende a ter algum efeito positivo na redução dos roubos a pedestres.

A seguir são analisados simultaneamente os atributos físico-espaciais e configuracionais dos segmentos nos dois turnos que concentram a maior quantidade de roubos a pedestres, nomeadamente os turnos da noite (55) e da tarde (43), totalizando 98 $(66,6 \%)$ de 147 roubos a pedestres nos quatro turnos. Assim, são considerados os atributos dos quatro segmentos (13886; 14842; 18039; 20019; Tabela 12) com as maiores quantidades de roubos a pedestres no turno da noite (entre os 10 considerados neste estudo), onde ocorreram 29 $(52,7 \%)$ do total dos 55 roubos no turno da noite nos 10 segmentos. As quantidades de roubos a pedestres em cada um desses quatro segmentos, incluídos, entre parênteses, aqueles roubos que ocorreram antes do horário de fechamento do comércio (20h), são: 13886-10 (3); 14842-7 (3); 18039-6 (1); e 20019-6 (3). Logo, dos 29 roubos a pedestres apenas 10 (34,48\%) ocorreram antes no horário de fechamento do comércio, indicando que a existência de lojas abertas no segmento durante a noite contribui para a redução desse tipo de crime. Os valores dos atributos para cada um dos quatro segmentos com mais roubos no turno da noite revelam que tais atributos se caracterizam por baixos valores, com exceção dos valores de integração global, do valor médio de integração local do segmento 13886, do valor alto de escolha global do segmento 20019, da taxa média de serviços nos pavimentos térreos do segmento 13886 e da taxa média de atividade comercial nos pavimentos térreos do segmento 20019 (Tabela 12).

A análise simultânea dos atributos físico-espaciais e configuracionais dos três segmentos (13886; 18370; 20018; Tabela 12) com as maiores quantidades de roubos a pedestres no turno da tarde (entre os 10 considerados neste estudo), onde ocorreram 24 (55,8\%) do total dos 43 roubos no turno da tarde nos 10 segmentos, revela que 11 roubos a pedestres ocorreram no segmento 13886 , 7 ocorreram no segmento 18370, e 6 roubos a pedestres ocorreram no turno da tarde no segmento 20018. Os valores dos atributos para cada um dos três segmentos com mais roubos no turno da tarde revelam que tais atributos também se caracterizam por baixos valores, com exceção dos valores de integração global, do valor médio de integração local do segmento 13886 e do alto valor de escolha global do segmento 20018 (Tabela 12).

\section{Conclusões}

O turno mais perigoso para um pedestre ser roubado nas quadras dos bairros considerados na região central de Porto Alegre é o da noite, seguido do turno da tarde, coincidindo com os resultados obtidos em outro estudo realizado em Porto Alegre, com dados da Secretaria de Segurança Pública do Rio Grande do Sul (QUINTANA, 2013), e no Bairro da Boa Viagem em Recife, com dados fornecidos pela Secretaria de Defesa Social de Pernambuco (MONTEIRO; CAVALCANTI, 2017). A manhã é o turno menos perigoso para caminhar nas quadras analisadas em Porto Alegre, sendo mais seguro caminhar pela manhã do que durante a tarde, conforme também evidenciado pelo estudo em Recife (MONTEIRO; CAVALCANTI, 2017). A quarta-feira aparece como o dia da semana mais inseguro, seguida de perto pelo sábado, quintafeira e sexta-feira, enquanto o domingo é claramente o dia menos inseguro, seguido dos dois dias do início da semana (segunda-feira e terçafeira), talvez por que existam mais pessoas saindo à noite e sujeitas a roubos a partir do meio para o final da semana. Setembro, seguido de perto pelo mês de junho, é o mês mais perigoso, enquanto dezembro, seguido de perto por janeiro, fevereiro, maio, outubro e novembro, é o mês menos perigoso para andar nas ruas, o que sugere uma tendência de meses quentes, quando há mais pessoas andando nas ruas, serem menos inseguros quanto a roubos a pedestres, já que tais crimes tendem a se beneficiar quando há poucas pessoas nos espaços abertos públicos. 
Tabela 11 - Taxas de atividade comercial nos pavimentos térreos e roubos a pedestres nos segmentos

\begin{tabular}{|c|c|c|c|c|c|c|c|c|}
\hline & $\begin{array}{c}\text { Segmentos } \\
\text { sem roubo } \\
\text { a pedestre } \\
\text { em todos } \\
\text { os turnos } \\
(30)\end{array}$ & $\begin{array}{c}\text { Segmentos } \\
\text { com mais } \\
\text { roubos a } \\
\text { pedestres } \\
\text { pela } \\
\text { manhã } \\
(10) \\
\end{array}$ & $\begin{array}{l}\text { Segmentos } \\
\text { sem roubo } \\
\text { a pedestre } \\
\text { em todos } \\
\text { os turnos } \\
(30)\end{array}$ & $\begin{array}{c}\text { Segmentos } \\
\text { com mais } \\
\text { roubos a } \\
\text { pedestres } \\
\text { à tarde } \\
(10)\end{array}$ & $\begin{array}{c}\text { Segmentos } \\
\text { sem roubo } \\
\text { a pedestre } \\
\text { em todos } \\
\text { os turnos } \\
(30)\end{array}$ & $\begin{array}{c}\text { Segmentos } \\
\text { com mais } \\
\text { roubos a } \\
\text { pedestres } \\
\text { à noite } \\
(10)\end{array}$ & $\begin{array}{c}\text { Segmentos } \\
\text { sem roubo } \\
\text { a pedestre } \\
\text { em todos } \\
\text { os turnos } \\
(30)\end{array}$ & $\begin{array}{c}\text { Segmentos } \\
\text { com mais } \\
\text { roubos a } \\
\text { pedestres } \\
\text { na } \\
\text { madrugada } \\
\quad(10) \\
\end{array}$ \\
\hline & \multicolumn{2}{|c|}{$\begin{array}{l}\text { Taxa de atividade } \\
\text { comercial no térreo } \\
\text { durante a manhã }\end{array}$} & \multicolumn{2}{|c|}{$\begin{array}{c}\text { Taxa de atividade } \\
\text { comercial no térreo } \\
\text { durante a tarde }\end{array}$} & \multicolumn{2}{|c|}{$\begin{array}{c}\text { Taxa de atividade } \\
\text { comercial no térreo } \\
\text { durante a noite }\end{array}$} & \multicolumn{2}{|c|}{$\begin{array}{l}\text { Taxa de atividade } \\
\text { comercial no térreoo } \\
\text { durante a madrugada }\end{array}$} \\
\hline $\begin{array}{l}\text { Taxa } \\
\text { mais alta }\end{array}$ & 0,062 & 0,031 & 0,124 & 0,013 & 0,031 & 0,013 & 0,010 & 0,005 \\
\hline $\begin{array}{l}\text { Taxa } \\
\text { mais } \\
\text { baixa }\end{array}$ & 0,000 & 0,000 & 0,000 & 0,000 & 0,000 & 0,000 & 0,000 & 0,000 \\
\hline $\begin{array}{l}\text { Taxa } \\
\text { média }\end{array}$ & 0,024 & 0,005 & 0,046 & 0,004 & 0,009 & 0,002 & 0,001 & 0,001 \\
\hline $\begin{array}{l}\text { Taxas } \\
\text { altas } \\
\text { rates } \\
(0,083- \\
0,124)\end{array}$ & $0(0 \%)$ & $0(0 \%)$ & $6(20 \%)$ & $0(0 \%)$ & $0(0 \%)$ & $0(0 \%)$ & $0(0 \%)$ & $0(0 \%)$ \\
\hline $\begin{array}{l}\text { Taxas } \\
\text { médias } \\
(0,042- \\
0,082)\end{array}$ & $6(20 \%)$ & $0(0 \%)$ & $\begin{array}{c}10 \\
(33,33 \%)\end{array}$ & $0(0 \%)$ & $0(0 \%)$ & $0(0 \%)$ & $0(0 \%)$ & $0(0 \%)$ \\
\hline $\begin{array}{l}\text { Taxas } \\
\text { baixas } \\
(0,000- \\
0,041)\end{array}$ & 24 (80\%) & $\begin{array}{c}10 \\
(100 \%)\end{array}$ & $\begin{array}{c}14 \\
(46,67 \%)\end{array}$ & $\begin{array}{c}10 \\
(100 \%)\end{array}$ & $\begin{array}{c}30 \\
(100 \%)\end{array}$ & $\begin{array}{c}10 \\
(100 \%)\end{array}$ & $\begin{array}{c}30 \\
(100 \%)\end{array}$ & $10(100 \%)$ \\
\hline
\end{tabular}

Nota: as taxas de atividade comercial nos pavimentos térreos variam de 0,000 a 0,124 em um grupo com 58 segmentos diferentes; as atividades comerciais nos pavimentos térreos podem variar conforme o turno.

Tabela 12 - Valor dos atributos dos segmentos com mais roubos a pedestres durante a noite e a tarde

\begin{tabular}{l|c|c|c|c|c|c|c}
\hline & \multicolumn{3}{c|}{$\begin{array}{c}\text { Segmentos com mais roubos a } \\
\text { pedestres à noite }\end{array}$} & \multicolumn{2}{c}{$\begin{array}{c}\text { Segmentos com mais } \\
\text { roubos a pedestres à } \\
\text { tarde }\end{array}$} \\
\hline \multicolumn{1}{c|}{ ATRIBUTOS } & $\mathbf{1 3 8 8 6}$ & $\mathbf{1 4 8 4 2}$ & $\mathbf{1 8 0 3 9}$ & $\mathbf{2 0 0 1 9}$ & $\mathbf{1 3 8 8 6}$ & $\mathbf{1 8 3 7 0}$ & $\mathbf{2 0 0 1 8}$ \\
& $\mathbf{( 1 0 )}$ & $\mathbf{( 7 )}$ & $\mathbf{( 6 )}$ & $\mathbf{( 6 )}$ & $\mathbf{( 1 1 )}$ & $\mathbf{( 7 )}$ & $\mathbf{( 6 )}$ \\
\hline integração global & médio & alto & médio & alto & médio & alto & alto \\
\hline integração local & médio & baixo & baixo & baixo & médio & baixo & baixo \\
\hline escolha global & baixo & baixo & baixo & alto & baixo & baixo & alto \\
\hline escolha local & baixo & baixo & baixo & baixo & baixo & baixo & baixo \\
\hline taxa postes de luz & baixo & baixo & baixo & baixo & baixo & baixo & baixo \\
\hline taxa conexão física & baixo & baixo & baixo & baixo & baixo & baixo & baixo \\
\hline taxa conexão visual & baixo & baixo & baixo & baixo & baixo & baixo & baixo \\
\hline taxas edif. uso misto & baixo & baixo & baixo & baixo & baixo & baixo & baixo \\
\hline taxas edif. uso residencial & baixo & baixo & baixo & baixo & baixo & baixo & baixo \\
\hline taxas edif. uso comercial/serviços & baixo & baixo & baixo & baixo & baixo & baixo & baixo \\
\hline taxa uso residencial no térreo & baixo & baixo & baixo & baixo & baixo & baixo & baixo \\
\hline taxa uso serviços no térreo & médio & baixo & baixo & baixo & baixo & baixo & baixo \\
\hline taxa uso comercial no térreo & baixo & baixo & baixo & média & baixo & baixo & baixo \\
\hline
\end{tabular}

A tendência de o roubo a pedestre ser mais intenso em segmentos mais longos, tal como identificada em outras pesquisas (HILLIER; SAHBAZ, 2005; QUINTANA, 2013), foi confirmada neste estudo, principalmente em segmentos maiores que $150 \mathrm{~m}$, enfatizando a relação entre a distância percorrida e o tempo de exposição ao risco, conforme já destacado por Hillier e Sahbaz (2005). Por outro lado, a conectividade dos segmentos não aparece como um aspecto que afete o roubo a pedestre e, 
portanto, está de acordo com o fato de que “[...] conectividade do segmento não prediz movimento, como comumente acreditado [...]" (HILLIER; SAHBAZ, 2012, p. 135).

Contrariamente a alguns estudos, nos quais casas localizadas em áreas globalmente integradas tendem a ser menos vulneráveis que aquelas situadas em áreas globalmente segregadas (SHU, 2009), o roubo a pedestre tende a ocorrer em segmentos com altos valores de integração global, tal como observado em pesquisa realizada por Quintana (2013). Esse resultado também é corroborado pela existência de um maior número de roubos a pedestres durante a noite em segmentos com valores mais altos de integração global em estudo realizado em dois bairros de Porto Alegre acerca da relação entre variáveis físico-espaciais e quatro tipos de crimes nas ruas, incluindo roubo a pedestre (REIS; ANDORFFY; MARCON, 2015). Contudo, esses roubos a pedestres podem ter ocorrido após o fechamento da maior parte do comércio no turno da noite em tais segmentos mais integrados, onde as atividades comerciais tendem a se concentrar nas cidades, com os assaltantes beneficiando-se da presença de potenciais vítimas e da redução gradativa, a partir do fechamento das lojas, da vigilância por parte de outras pessoas nas ruas. Nesse sentido, a análise realizada no presente estudo com os quatro segmentos que concentram a maior parte dos roubos a pedestres durante a noite mostra que a clara maioria dos roubos aconteceu após o encerramento do comércio em tais segmentos. Adicionalmente, em estudo realizado em Caxias do Sul (FIGUEIREDO, 2018), nas quadras com mais atividades comerciais e com as maiores taxas de conexões físicas e visuais, os crimes ocorreram após o fechamento da maioria das lojas.

Por sua vez, não foi encontrada evidência conclusiva acerca do efeito da integração local sobre as ocorrências de roubos a pedestres, embora essas ocorrências nos turnos da tarde, tal como em outro estudo (QUINTANA, 2013), e da noite possam ser facilitadas em segmentos com valores mais altos de integração local, em contraste com os resultados do estudo (REIS; ANDORFFY; MARCON, 2015) no qual valores mais altos de integração local estavam relacionados a uma diminuição no roubo a pedestre durante a noite.

Também não foi encontrado efeito conclusivo dos valores de escolha global sobre as ocorrências de roubos a pedestres, embora tais ocorrências pareçam ser facilitadas em segmentos com valores de escolha global mais altos. Entretanto, em outra pesquisa (REIS; ANDORFFY; MARCON, 2015) os valores mais altos de escolha global estavam relacionados à redução nos roubos a pedestres durante a manhã. Os resultados relativos à escolha local também não apresentam uniformidade. Contudo, os roubos a pedestres no turno da tarde cresceram com o aumento dos valores de escolha local, tal como os resultados relativos ao turno da noite em outro estudo (REIS; ANDORFFY; MARCON, 2015).

Com relação ao número de conexões físicas entre as edificações e a rua, fica evidenciado seu impacto positivo na redução da quantidade de roubos a pedestres no segmento (nos turnos da manhã, tarde e noite), corroborando o fato, revelado em outro estudo (REIS; ANDORFFY; MARCON, 2015), de haver redução nos roubos a pedestres durante a noite com o aumento na taxa de conexões físicas em um segmento. Os resultados ainda indicam a necessidade de acessos a edificações em intervalos menores do que $13 \mathrm{~m}$ para que tais conexões físicas possam contribuir para a redução dos roubos a pedestres.

Por sua vez, a quantidade de conexões visuais entre as edificações e as ruas também aparece como um importante indicador do número de roubos a pedestres durante os turnos da manhã, tarde e noite, corroborando o resultado de estudo realizado em Maceió (DELFINO, 2017), onde algumas características, como a baixa permeabilidade visual, são inerentes a espaços com altas taxas de crimes nas ruas. Adicionalmente, os resultados estão em sintonia com a menção por Jane Jacobs (1984), em seu estudo pioneiro, acerca do efeito positivo da vigilância informal dos espaços abertos públicos pelos usuários das edificações adjacentes ("olhos para a rua”), somada à vigilância pelas próprias pessoas nos espaços abertos ("olhos na rua”), na redução de crimes em tais espaços públicos. A redução nos roubos a pedestres é evidente quando mais de $19 \%$ do total do comprimento dos dois lados do segmento apresenta conexões visuais entre as edificações e os espaços abertos públicos das ruas. Esses resultados também são sustentados pelo fato de $71 \%$ dos infratores entrevistados (204) em estudo realizado no Paraná preferirem ruas com muros (com, no máximo, $2 \mathrm{~m}$ ) do que com grades (com, no máximo, $2 \mathrm{~m}$ ) em razão de os muros ocultarem suas ações $(54 \%$ - 110) e de serem mais facilmente transpostos $(24 \%$ - 49) do que grades (BONDARUK, 2008). Assim, a redução nas conexões visuais, além de favorecer os roubos a pedestres, também tende a facilitar a ocorrência de outros tipos de crimes, como roubos a residências. Ainda, vão ao encontro desses resultados aqueles que mostram que a percepção de segurança, em três percursos apresentados em vídeo em estudo realizado em Caxias do Sul (FIGUEIREDO, 2018), diminui conforme diminuem as taxas de conexões físicas e visuais entre as edificações e os espaços 
abertos públicos em tais percursos. As conexões físicas e visuais permitem a percepção por parte dos pedestres da existência de prováveis refúgios e da possibilidade de serem vistos ou ouvidos por pessoas nas edificações, o que gera maior percepção de segurança nos espaços abertos públicos.

O número de portas de garagem e a existência de barreiras físicas e visuais em um segmento não foram identificados como facilitadores específicos de roubo a pedestre nos três turnos do dia, com exceção da tendência de os roubos a pedestres aumentarem no turno da manhã à medida que as barreiras físicas e visuais aumentam. Com relação à iluminação pública, a redução dos roubos a pedestres durante os turnos da noite e da madrugada está relacionada a uma rua mais bem iluminada, havendo o potencial de redução desses roubos em tais turnos quando os postes de luz estão posicionados no segmento de rua em intervalos menores do que 14,5 m. Esse resultado é sustentado pelos de outros estudos, tais como o efeito positivo da existência de postes de luz na redução de roubos a pedestres durante a madrugada (REIS; ANDORFFY; MARCON, 2015) e o favorecimento na ocorrência de delitos nas ruas devido a uma iluminação pública ineficiente (DELFINO, 2017).

Os usos das edificações também tendem a ter impacto sobre as ocorrências de roubos a pedestres. Assim, a existência de edificações de uso misto em um segmento tende a ter um efeito positivo na redução dos roubos a pedestres em qualquer um dos três turnos do dia. Uma distância média igual ou menor a $59 \mathrm{~m}$ entre os acessos a tais edificações em ambos os lados do segmento possui o potencial de diminuir as ocorrências de roubos a pedestres. Por sua vez, o roubo a pedestres no turno da manhã, da tarde e da noite é facilitado em segmentos com taxas de edificações de uso residencial muito baixas, havendo o potencial de redução desses roubos com a existência de acesso a uma edificação com uso residencial em intervalos inferiores a $50 \mathrm{~m}$ no total do comprimento do segmento. Além disso, distâncias médias entre acessos a edificações de uso comercial/serviço menores que $62,5 \mathrm{~m}$ têm a tendência a reduzir as ocorrências de roubos a pedestres.

Com relação aos usos nos pavimentos térreos voltados para a rua, a existência de atividades residenciais nos térreos em distâncias médias não superiores a $43 \mathrm{~m}$ tende a desencorajar as ocorrências de roubos a pedestres, principalmente no turno da tarde. Adicionalmente, a existência de atividades de serviço no térreo em uma distância média menor do que $100 \mathrm{~m}$ tende a reduzir as ocorrências de roubos a pedestres particularmente no turno da tarde. Entretanto, os roubos a pedestres durante a noite tendem a aumentar com o aumento na taxa de atividades de serviço nos térreos das edificações durante este turno. Isso pode acontecer devido ao fato de que as atividades de serviço durante a noite não são suficientes para gerar presença intensa de pessoas. Portanto, os pedestres não estão protegidos pela presença de outras pessoas nesses segmentos, principalmente quando algumas dessas atividades já estão encerradas. Conforme já destacado (CHIARADIA; HILLIER; SCHWANDER, 2009), o risco de ser selecionado como alvo para um assalto aumenta com a redução do número de pessoas no segmento. Por outro lado, a existência de atividades comerciais nos pavimentos térreos em distâncias médias não superiores a $24 \mathrm{~m}$ tende a desencorajar as ocorrências de roubos a pedestres.

Esses resultados corroboram o que já havia sido destacado por Jane Jacobs (1984) com relação ao efeito benéfico da diversidade de usos para a segurança urbana e estão em sintonia com a Teoria das Atividades Rotineiras (COHEN; FELSON, 1979), que condiciona a ocorrência de um crime a três requisitos, nomeadamente um agressor motivado, um alvo apropriado e ausência de protetores, que podem ser policiais/guardas (formais) ou pessoas nos espaços abertos públicos e nas edificações adjacentes (informais). Assim, a menor presença desses protetores informais nos espaços abertos públicos e no interior de edificações, assim como a redução das conexões físicas e visuais entre tais edificações e os espaços abertos públicos favorecem as ocorrências de roubos a pedestres. Sintetizando, locais desassistidos possibilitam a proximidade do agressor com o alvo (COHEN; FELSON, 1979). Logo, segmentos de ruas pouco iluminados, com baixos níveis de conexão física e visual entre as edificações e os espaços abertos públicos, com pouca quantidade de edificações de uso misto, residencial e comercial/serviços, e com pequena quantidade de usos residenciais e de atividades de serviços e comerciais nos pavimentos térreos tendem a potencializar as ocorrências de roubos a pedestres.

Portanto, os resultados apresentados sobre os segmentos sem roubo a pedestre e sobre aqueles que concentram as maiores quantidades de roubos a pedestres nos diferentes turnos auxiliam no esclarecimento acerca dos valores dos atributos físico-espaciais e configuracionais que mais facilitam ou dificultam as ocorrências de tais roubos, possibilitando o aprofundamento do conhecimento sobre as relações entre esses aspectos.

Este estudo pode contribuir, particularmente, quanto ao tipo de quantificação das variáveis consideradas, tal como o percentual mínimo de 
conexão visual no segmento para desestimular a ocorrência de roubos a pedestres, o que tende a não ocorrer em outros estudos envolvendo atributos físico-espaciais dos segmentos e roubos a pedestres, tal como no estudo realizado no Bairro da Boa Viagem em Recife (MONTEIRO; CAVALCANTI, 2017).

Embora tenham sido identificados os horários de funcionamento das atividades nos térreos das edificações para que as taxas de tais atividades fossem calculadas, destaca-se como limitação deste estudo o fato de não ter sido considerada em todas as análises a distinção entre os horários de funcionamento da maioria do comércio e serviços no turno da manhã e da noite nos segmentos investigados. Nesse sentido, a desconsideração da relação entre o horário de ocorrência do crime e os horários de funcionamento dos estabelecimentos comerciais em uma quadra pode omitir o fato de que determinado crime ocorreu após o fechamento desses estabelecimentos e, assim, possibilitar a menção de uma relação entre uso comercial e ocorrências criminais sem que exista evidência para tal, como em alguns estudos (VIVAN; SABOYA, 2017). Logo, o horário de ocorrência do crime é fundamental para o entendimento das relações entre o crime e os atributos físico-espaciais e configuracionais de segmentos de ruas, já que tais atributos não são constantes durante as 24 horas do dia; em estudo realizado em Londres, Hillier e Sahbaz já ressaltavam: “[...] não caminhe nas ruas principais depois da meia-noite, mas não as deixe antes da meia-noite [...]" (HILLIER; SAHBAZ, 2005, p. 472).

Como recomendações para futuras pesquisas sugere-se a discriminação, nos turnos da manhã e da noite, dos horários nos quais a maioria do comércio e serviços está aberta, assim como os meses de tais ocorrências, já que, por exemplo, às 20h está claro no verão e escuro no inverno em Porto Alegre. Assim, no caso de Porto Alegre, seria possível considerar somente os meses de junho, julho, agosto e setembro (inverno) e de dezembro, janeiro, fevereiro e março (verão) em novos estudos acerca da relação entre variáveis físico-espaciais e roubos a pedestres. Ainda, conforme a Teoria das Janelas Quebradas (WILSON; KELLING, 1982), que destaca a relação existente entre áreas abandonadas, decadentes, degradadas e a ocorrência de crimes, também seria relevante considerar as percepções de usuários de determinada área acerca de sua aparência e de sua qualidade urbana e identificar indicadores de problemas tais como edificações abandonadas, janelas com vidros quebrados, pichações e espaços abertos mal mantidos. Áreas com tais características provocam um aumento da percepção de insegurança e consequente medo e podem estimular a ocorrência inicial de crimes menores (p. ex., vandalismo), que podem evoluir para crimes mais graves, como roubos a pedestres (WILSON; KELLING, 1982). Adicionalmente, a percepção de segurança por parte dos usuários da cidade é um aspecto importante por si só, pois, se determinadas áreas são percebidas como inseguras, mesmo que as ocorrências de roubos a pedestres sejam inexistentes ou muito baixas, haverá redução do uso de tal área (VIEIRA, 2002) e, logo, tal área tenderá a ter menos vitalidade e qualidade urbana.

\section{Referências}

BONDARUK, R. A Prevenção do Crime

Através do Desenho Urbano. Curitiba: Edição do Autor, 2008.

CALDEIRA, T. Cidade de Muros: crime, segregação e cidadania em São Paulo. São Paulo: Editora 34; Edusp, 2000.

CECCATO, V.; OBERWITTLER, D. Comparing Spatial Patterns of Robbery: evidence from a Western and an Eastern European city. Cities, v. 25, n. 4, p. 185-196, 2008.

CHIARADIA, A.; HILLIER, B.; SCHWANDER, C. Spatial Economics of Crime: spatial design factors and the total social cost of crime against individuals and property in London. In: INTERNATIONAL SPACE SYNTAX SYMPOSIUM, 7., Stockholm, 2009. Proceedings... Stockholm: Royal Institute of Technology, 2009.

COHEN, L. E.; FELSON, M. Social Change and Crime Rate Trends: a routine activity approach. American Sociological Review, v. 44, p. 588-608, 1979.

DELFINO, M. S. Entre Muros: descrição espacial dos cenários urbanos com grande incidência criminal no bairro do Tabuleiro do Martins. Maceió, 2017. 158 f. Dissertação (Mestrado em Arquitetura e Urbanismo) - Programa de PósGraduação em Arquitetura e Urbanismo, Universidade Federal de Alagoas, Maceió, 2017.

FIGUEIREDO, C. A. Interfaces Térreas Entre Edificações e Espaços Abertos Públicos: efeitos para estética, uso e percepção de segurança urbana. Porto Alegre, 2018. 275 f. Dissertação (Mestrado em Planejamento Urbano e Regional) - Programa de Pós-Graduação em Planejamento Urbano e Regional, Universidade Federal do Rio Grande do Sul, Porto Alegre, 2018.

HILLIER, B.; HANSON, J. The Social Logic of Space. Cambridge: Cambridge University Press, 1984. 
HILLIER, B. Using Depthmap for Urban

Analysis: a simple guide on what to do once you have an analysable map in the system. London: MSc Advanced Architectural Studies, 2007.

HILLIER, B.; SAHBAZ, O. Safety in Numbers: high resolution analysis of crime patterns in urban street networks. In: CECCATO, V. (Ed.). The Urban Fabric of Crime and Fear. Dordrecht: Springer, 2012.

HILLIER, B.; SAHBAZ, O. High Resolution Analysis of Crime Patterns in Urban Street Networks: an initial statistical sketch from an ongoing study of a London Borough. In: INTERNATIONAL SPACE SYNTAX SYMPOSIUM, 5., Delft, 2005. Proceedings... Delft: University of Technology, 2005.

HILLIER, B.; IIDA, S. Network and Psychological Effects in Urban Movement. In: COHN, A. G.; MARK, D. M. (Ed.). Spatial Information Theory - COSIT 2005: lecture notes in computer science. Berlin; Heidelberg: Springer, 2005.

JACOBS, J. The Death and Life of Great American Cities: the failure of town planning. Harmondsworth: Penguin, 1984.

LIRA, P. S. Geografia do Crime e Arquitetura do Medo: uma análise dialética da criminalidade violenta e das instâncias urbanas. Rio de Janeiro: Letra Capital, 2014.

MONTEIRO, C.; CAVALCANTI, R. Perfis Espaciais Urbanos para Avaliação de Lugares Vulneráveis ao Crime. In: NETTO, V. et al. (Ed.). Efeitos da Arquitetura: os impactos da urbanização contemporânea no Brasil. Brasília: FRBH, 2017.

MONTEIRO, C.; IANNICELLI, C. Spatial Profiles of Urban Crimes: the role of morphology in a context of social inequality. In: INTERNATIONAL SPACE SYNTAX SYMPOSIUM, 7., Stockholm, 2009.

Proceedings... Stockholm: Royal Institute of Technology, 2009.

NEWMAN, O. Defensible Space: crime prevention through urban design. New York: Macmillan, 1972.

NEWMAN, O. Design Guidelines for Creating Defensible Space. Washington, DC: US GPO, National Institute of Law Enforcement and Criminal Justice, 1976.

POYNER, B.; WEBB, B. Crime Free Housing. Oxford: Butterworth-Architecture, 1991.
QUINTANA, E. Influência de Características Físico-Espaciais na Ocorrência de Crimes e na Percepção de Segurança em Áreas Residenciais Com Condomínios Fechados. Porto Alegre, 2013. 290 f. Dissertação (Mestrado em Planejamento Urbano e Regional) - Programa de Pós-Graduação em Planejamento Urbano e Regional, Universidade Federal do Rio Grande do Sul, Porto Alegre, 2013.

REIS, A. T.; ANDORFFY, T.; MARCON, L. Relationship Between Some Physical Spatial Variables and Four Types of Street Crimes. In: INTERNATIONAL SPACE SYNTAX SYMPOSIUM, 10., London, 2015. Proceedings... London: Space Syntax Laboratory, The Bartlett School of Architecture, 2015.

REIS, A. T.; DITTMAR, C. On the Relationship Between Crime in Residential Areas and Street Segment Attributes. In: KABISCH, S. et al. (Ed.). Vulnerability, Risks, and Complexity: impacts of global change on human habitats - series: advances in people-environment studies, volume 3. Göttingen: Hogrefe, 2012.

SAHBAZ, Ö.; HILLIER, B. The Story of the Crime: functional, temporal and spatial tendencies in street robbery. In: INTERNATIONAL SPACE SYNTAX SYMPOSIUM, 6., Istanbul, 2007. Proceedings... Istanbul: Istanbul Technical University, 2007.

SHU, C. Spatial Configuration Of residential Area and Vulnerability of Burglary Case Studies From UK and Taiwan. In: INTERNATIONAL SPACE SYNTAX SYMPOSIUM, 7., Stockholm, 2009. Proceedings... Stockholm: Royal Institute of Technology, 2009.

VAN NES, A.; LÓPEZ, M. J. Macro and Micro Scale Spatial Variables and the Distribution of Residential Burglaries and Theft From Cars: an investigation of space and crime in the Dutch cities of Alkmaar and Gouda. The Journal of Space Syntax, v. 1, n. 2, p. 296-314, 2010.

WILSON, J.; KELLING, G. Broken Windows: the police and neiborghood safety. The Atlantic Monthly, v. 249, n. 3, p. 29-38, 1982.

VIEIRA, L. B. Influência do Espaço Construído na Ocorrência de Crimes em Conjuntos Habitacionais. Porto Alegre, 2002. $310 \mathrm{f}$. Dissertação (Mestrado em Planejamento Urbano e Regional) - Programa de Pós-Graduação em Planejamento Urbano e Regional, Universidade Federal do Rio Grande do Sul, Porto Alegre, 2002. 
VIVAN, M.; SABOYA, R. Arquitetura, Espaço Urbano e Criminalidade: efeitos de visibilidade na distribuição de ocorrência de crimes. In: NETTO, V. et al. (Ed.). Efeitos da Arquitetura: os impactos da urbanização contemporânea no Brasil. Brasília: FRBH, 2017.
VOORDT, D.; WEGEN, H. The Delft Checklist on Safe Neighborhoods. Journal of Architectural and Planning Research, v. 10, n. 5, p. 341-356, 1993.

ZALUAR, A. Da revolta ao Crime S.A. São Paulo: Moderna, 2002.

Antônio Tarcísio da Luz Reis

Departamento de Arquitetura, Faculdade de Arquitetura | Universidade Federal do Rio Grande do Sul | Rua Sarmento Leite, 320, Cemtro | Porto Alegre - RS - Brasil | CEP 90050-170 | Tel.: (51) 3308-4529 | E-mail: tarcisio@orion.ufrgs.br

\section{Clarel Fernando Ely J unior}

Faculdade de Arquitetura | Universidade Federal do Rio Grande do Sul | Porto Alegre - RS - Brasil | E-mail: clarel.ely@hotmail.com

\section{Camila da Silva Eisenhut}

Faculdade de Arquitetura | Universidade Federal do Rio Grande do Sul | Porto Alegre - RS - Brasil | E-mail: eisenhutnht@gmail.com

Revista Ambiente Construído

Associação Nacional de Tecnologia do Ambiente Construído

Av. Osvaldo Aranha, 99 - 3o andar, Centro

Porto Alegre - RS - Brasil

$$
\text { CEP } 90035-190
$$

Telefone: +55 (51) 3308-4084

Fax: +55 (51) 3308-4054

www. seer. ufrgs. br/ ambienteconstruido

E-mail: ambienteconstruido@ufrgs.br

(c) (i) This is an open-access article distributed under the terms of the Creative Commons Attribution License. 